\title{
An Assessment of Circulating Chromogranin A as a Biomarker of Bronchopulmonary Neuroendocrine Neoplasia: A Systematic Review and Meta-Analysis
}

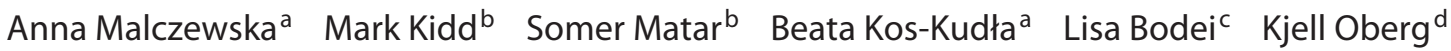 \\ Irvin M. Modline \\ a Department of Endocrinology and Neuroendocrine Tumors, Medical University of Silesia, Katowice, Poland; \\ bWren Laboratories, Branford, CT, USA; ${ }^{\mathrm{C} M e m o r i a l}$ Sloan Kettering Cancer Centre, New York, NY, USA; \\ ${ }^{d}$ Department of Endocrine Oncology, University Hospital, Uppsala, Sweden; eYale University School of Medicine, \\ New Haven, CT, USA
}

\section{Keywords}

Chromogranin A · Carcinoid · Small-cell lung cancer · Lung ·

Meta-analysis

\begin{abstract}
Background: Management of bronchopulmonary neuroendocrine neoplasia (NEN; pulmonary carcinoids [PCs], smallcell lung cancer $[\mathrm{SCLC}]$, and large cell neuroendocrine carcinoma) is hampered by the paucity of biomarkers. Chromogranin A $(\mathrm{CgA})$, the default neuroendocrine tumor biomarker, has undergone wide assessment in gastroenteropancreatic neuroendocrine tumors. Objectives: To evaluate $\mathrm{CgA}$ in lung NEN, define its clinical utility as a biomarker, assess its diagnostic, prognostic, and predictive efficacy, as well as its accuracy in the identification of disease recurrence. Methods: A systematic review of PubMed was undertaken using the preferred reporting items for systematic reviews and meta-analyses guidelines. No language restrictions were applied. Overall, 33 original scientific papers and 3 case reports, which met inclusion criteria, were included in
\end{abstract}

\section{KARGER}

() 2019 S. Karger AG, Basel

E-Mail karger@karger.com

www.karger.com/nen qualitative analysis, and meta-analysis thereafter. All studies, except 2, were retrospective. Meta-analysis statistical assessment by generic inverse variance methodology. Results: Ten different $\mathrm{CgA}$ assay types were reported, without consistency in the upper limit of normal (ULN). For PCs ( $n=16$ studies; median patient inclusion 21 [range 1-200, total: 591 patients]), the $\mathrm{CgA}$ diagnostic sensitivity was $34.5 \pm 2.7 \%$ with a specificity of $93.8 \pm 4.7$. CgA metrics were not available separately for typical or atypical carcinoids. $\mathrm{CgA}>100 \mathrm{ng} / \mathrm{mL}$ $(2.7 \times$ ULN) and $>600 \mathrm{ng} / \mathrm{mL}$ (ULN unspecified) were anecdotally prognostic for overall survival $(n=2$ retrospective studies). No evidence was presented for predicting treatment response or identifying post-surgery residual disease. For SCLC ( $n=19$ studies; median patient inclusion 23 [range 5-251, total: 1,241 patients]), the mean diagnostic sensitivity was $59.9 \pm 6.8 \%$ and specificity $79.4 \pm 3.1$. Extensive disease typically exhibited higher CgA levels (diagnostic accuracy: $61 \pm 2.5 \%)$. An elevated CgA was prognostic for overall sur-

Irvin M. Modlin, MD, PhD

650 Park Avenue

New York, NY 10021 (USA)

E-Mail imodlin@optonline.net

Kjell Öberg, MD, PhD

Department of Endocrine Oncology

University Hospital

SE-75185 Uppsala (Sweden)

E-Mail kjell.oberg@ medsci.uu.se 
vival ( $n=4$ retrospective studies). No prospective studies evaluating predictive benefit or prognostic utility were identified. Conclusion: The available data are scarce. An assessment of all published data showed that $\mathrm{CgA}$ exhibits major limitations as an effective and accurate biomarker for either PC or SCLC. Its utility especially for localized PC/limited SCLC (when surgery is potentially curative), is limited. The clinical value of $\mathrm{CgA}$ remains to be determined. This requires validated, well-constructed, multicenter, prospective, randomized studies. An assessment of all published data indicates that $\mathrm{CgA}$ does not exhibit the minimum required metrics to function as a clinically useful biomarker for lung NENs.

(c) 2019 S. Karger AG, Basel

\section{Introduction}

Management of the patients with bronchopulmonary neuroendocrine neoplasia (NEN) is difficult since there is a paucity of biomarkers to facilitate diagnosis and followup. NEN constitutes one-fourth of primary lung neoplasia and are a heterogeneous group of tumors which share a neuroendocrine (NE) origin. Chromogranin $\mathrm{A}(\mathrm{CgA})$ is the most commonly used biomarker for NE disease, although its utility has been mostly assessed in gastroenteropancreatic neuroendocrine tumors (GEP-NETs). Given the overlapping cell of origin - NE - CgA has been examined in BPNETs. The aim of this study was to comprehensively assess the clinical utility of $\mathrm{CgA}$ as a biomarker for lung NEN. We sought to evaluate its capability as a diagnostic and prognostic tool, and whether measurements could be used to predict treatment response or disease recurrence. We performed a systematic review and rigorous meta-analysis of the available published data.

\section{Lung NEN}

\section{Epidemiology}

Lung NEN encompasses a heterogeneous group of well-differentiated pulmonary carcinoids (PCs), typical (TC), or atypical (AC), and high-grade tumors, such as small-cell lung cancer (SCLC), and large cell neuroendocrine carcinoma (LCNEC) [1]. In the current WHO 2015 Classification of the Lung Tumors, they are grouped together along with preinvasive lesions diffuse idiopathic pulmonary neuroendocrine cell hyperplasia [2]. Their incidence has been rising over the last 3 decades likely reflecting wider awareness at a pathological level and advances in anatomic and functional imaging [3].

CgA in Lung NEN: A Meta-Analysis
Overall, these tumors represent $\sim 25 \%$ of all primary lung neoplasia. The most frequent lung NEN is SCLC (20\%), followed by LCNEC (3\%), TC (2\%), and AC (0.2\%) [4]. PCs represent $\sim 30 \%$ of all well-differentiated NETs and are the second most common after gastrointestinal tract NETs (66\%) [5]. PC (TC-low grade, AC-intermediate grade) exhibits distinct clinical, epidemiologic, histologic, and genetic differences compared to the higher grade SCLC and LCNEC $[6,7]$.

PC have more favorable prognosis (5-year survival, $\sim 88 \%$ for TC, and $\sim 50-80 \%$ for AC) than SCLC and LCNEC ( $<5 \%$ and $15-57 \%$, respectively) [4]. Despite the indolent nature of PC, long-term surveillance is recommended $[8,9]$, as the post-resection recurrence occurs in $5 \%$ of TC and $20 \%$ of AC [10]. TC metastasize $(\sim 15 \%$ cases), mostly to regional lymph nodes, within a median of 4 years. In contrast, $~ 50 \%$ of AC metastasize regionally or distantly within a median of 1.8 years to recurrence [8]. Accurate biomarkers to monitor tumor behavior are therefore of critical importance for the surveillance and overall management.

\section{Clinical Presentation}

The majority of PCs are localized centrally, in the main $(\sim 10 \%)$, or lobar bronchi $(\sim 75 \%)$, and the remainder peripherally [11]. While peripheral PC (mostly AC) are on most occasions incidental findings [11], the centrally localized PC (the majority are TC) may cause obstructive respiratory symptoms related to tumor mass (e.g., recurrent chest infections, cough, hemoptysis, chest pain, dyspnea, or wheezing), mimicking other respiratory diseases such as COPD or asthma [11]. In a minority of cases, hormonal hypersecretion with related symptomatology may lead to diagnosis. Cushing's syndrome occurs in 1-6\% of PC, syndrome of inappropriate antidiuretic hormone secretion is found in $5 \%$ of SCLC but rarely in PC. Carcinoid syndrome occurs in $2-5 \%$ of PC (compared to $~ 10 \%$ in GEP-NETs), most often when liver metastases are present [8]. PC occur in $\sim 5-13 \%$ of MEN-1 $[8,12]$, with the majority $(\sim 75 \%)$ being TC [12].

SCLC and LCNEC usually present at advanced stage with extensive lymphadenopathy and direct mediastinal invasion [3]. They are both highly aggressive tumors typically affecting elderly smokers [8]. These tumors manifest with large peripheral (LCNEC) or central pulmonary masses (SCLC). Due to advanced disease at presentation, affected patients may not be candidates for surgical resection, and are often treated with chemotherapy with or without radiation [13].

Neuroendocrinology 2020;110:198-216 DOI: $10.1159 / 000500525$ 


\section{Origin}

Understanding the normal cellular hierarchy within the lung is vital to identify the progenitor cells for neoplasia. The diffuse neuroendocrine system (DNES) comprises NE cells (originally called "Kulchitsky cells") spread throughout the gastrointestinal, bronchopulmonary, and urogenital tract [5]. Although its function and cellular ontogeny remain unclear, the DNES is considered to represent a monitoring system that regulates secretion, absorption, blood perfusion, and motility [14]. NE cells are involved in synthesis of specific peptides and amines, which are released via secretory granules and exocytosis, and regulate numerous biological processes in an autocrine, paracrine, and endocrine fashion [15]. CgA is a key modulator and its synthesis and precise biological role within the DNES is of particular interest. CgA exists in many molecular forms, exhibiting a range of biological functions (e.g., regulation of NE secretion, vasomotor activity, cardiovascular homeostasis, cardiac function, and modulatory roles in cell adhesion) $[14,16]$. As CgA has been identified throughout the DNES, it has been proposed as a biomarker of the pathophysiological processes including neoplasia that emanate from this system [14].

In the bronchopulmonary system, NE cells are spread as single pulmonary neuroendocrine cells (PNECs) or clusters, referred to as neuroepithelial bodies (NEBs). During lung development, PNECs differentiate from the primitive epithelium and form a viable population of cells that persist throughout life. In the healthy adult, PNECs are distributed from the larynx, trachea, and bronchi to the broncho-alveolar junction in a ratio of 1 PNEC per $~ 2,500$ epithelial cells. Both PNECs and NEBs exhibit similar phenotypes in respect of amine production (including $\mathrm{CgA}$ ) and neuropeptide dense-core vesicles. Upon stimulation, degranulation occurs and bioactive agents are exocytosed thus initiating local paracrine or neurocrine effects on neighboring cells, including activation of both extrinsic and intrinsic neurons. The precise function of PNECs, however, remains unclear, as well as the nature of the relationship between PNECs and NEBs. In general, PNECs are considered endocrine, paracrine, or receptor-secretory cells involved in neurohormonal regulation of pulmonary vascular or bronchial responses. In contrast, NEB function as chemoreceptors involved in hypoxia detection and activation of vagal afferents, thus enacting a significant role in pathobiological regulation of breathing [3].

A generalized proliferation of PNECs and NEBs, or a linear proliferation of PNECs, may result in diffuse idiopathic pulmonary neuroendocrine cell hyperplasia. This may develop as a reactive response to lung injury, oblit- erative bronchiolitis, interstitial lung disease, or in individuals with chronic cough, and so on. Should the proliferation of PNECs extend beyond the basement membrane, the aggregations are referred to as tumorlets. Nodules larger than $5 \mathrm{~mm}$ are classified as PCs [3]. PC and SCLC cells contain similar neurosecretory type granules, some of which are argentaffin under electron microscope, and tumor cells exhibit other features such as pseudopod-like cytoplasmic processes resembling the normal bronchial NE (Kulchitsky) cell counterparts [17]. NE cells from different sites vary in their affinity for silver stains but also produce different secretions and show different tendencies to undergo malignant transformation [18].

Overall, combining evidence from light-microscopic morphology, the electron microscope and hormonal similarities between PC and SCLC, and the close relationship between the 2 tumors suggest a common derivation from NE cells [17]. Although, NE cells are the predominant cells of origin of SCLC, it has not been determined whether SCLC arise from differentiated NE cells or from the stem/progenitor cells [19]. Tissue stem cells are considered attractive candidates for the cells of origin of tumors, as their long in vivo life span would accrue genetic mutations that drive tumorigenesis [20].

\section{Histology}

Histology remains the generally accepted standard of care for the diagnosis of lung NEN. Identification is based upon characteristic NE morphology and the immunohistochemical identification of NE markers (CgA, synaptophysin and CD56/neural cell adhesion molecule [NCAM]) [8]. Currently, CgA and synaptophysin are the most commonly used [21]. Differentiating features are small or large cell cytomorphology/histomorphology, nuclear criteria and the mitotic range (for TC $<2 / 2 \mathrm{~mm}^{2}$ ) and absence of necrosis, (for AC $2-10 / 2 \mathrm{~mm}^{2}$ ) and/or foci of punctate necrosis. LCNEC usually exhibit $>10 / 2 \mathrm{~mm}^{2}$, median 70 mitoses and SCLC $>10 / 2 \mathrm{~mm}^{2}$ with a median of 80 , both with extensive geographical necrosis. The WHO 2015 classification proposed Ki-67 proliferation rates for TC up to $5 \%$, AC up to $20 \%$, LCNEC $40-80 \%$, and for SCLC as $50-100 \%$ [22]. However, still the principal role of the proliferation index is to separate poorly differentiated tumors from PC, especially in small biopsies with crush artifact or the presence of necrosis. It does not allow reliable differentiation between $\mathrm{TC}$ and $\mathrm{AC}$. It may play a role as a prognostic factor in PC $[23,24]$. Overall, more data are needed to define its utility in lung NEN, as opposed to GEP-NETs, where the proliferation index has been considered an integral part of the grading system [8]. 


\section{Chromogranin A}

\section{General Characteristics}

CgA belongs to the family of acidic proteins - the granins - which constitute the major component of secretory granules of various endocrine and NE cells, which comprise the endocrine glands and DNES [25]. CgA was the first identified member of this family and its name derives from the original discovery in the catecholaminecontaining chromaffin granules of the adrenal medulla [26]. Among chromogranins, CgA has the widest NE distribution and is expressed in some cells that are negative for other granins, for example, chromogranin B or secretogranin II [15]. Its ubiquitous expression in NE tissues and cosecretion with neuropeptides and peptide hormones have been considered an important feature that would make it useful as a tissue and circulating pan-endocrine biomarker for NE disease [27].

Functionally, CgA is known to be involved in both the intracellular modulation of processing of peptide hormones/neuropeptides and directing them to the regulated pathway of secretion, as well as an extracellular functionary, as a precursor of biologically active peptides [15]. It plays regulatory roles in the endocrine, cardiovascular, immune system, the glucose, or calcium homeostasis [28]. Physiologically, the main source of $\mathrm{CgA}$ is the adrenal gland, where CgA is the major soluble protein of catecholamine secretory granules [25]. However, if a NET arises, the main blood source of $\mathrm{CgA}$ becomes the tumor itself [29]. Tumor secrete CgA as well as a wide variety of breakdown and processed fragments, which can be detected in $30-80 \%$ of NETs $[30,31]$. The metrics for specificity of assays range from 68 to $100 \%$ and for sensitivity $42-93 \%$ $[32,33]$. These results depend on the tumor primary site, grade, or disease burden [32,34]. The inability of CgA to attain acceptable metrics (consistent sensitivity $>80 \%$ and specificity $>90 \%$ ) as a clinical biomarker also reflects the numerous non-NE conditions that result in CgA elevation, as well as variations in the different assay methodologies, or falsely negative measurements [32, 35].

\section{Detection Methods}

A recognized international consensus for CgA measurements is not available [36]. Various commercially available assays are used for CgA detection, for example, enzymelinked immunosorbent assay (ELISA), immunoradiometric assay (IRMA), or radioimmunoassay (RIA). Different techniques of CgA assays, or utilized antibodies (monoclonal vs. polyclonal) detecting various epitopes of the protein surface, contribute to the variations in the published results
$[35,37]$. In general, measurement of an intact plasma CgA has greater sensitivity than detection of its fragments [36]. Comparison of 3 commercially available kits (CGA-RIA CT; CIS bio international, Gif-sur-Yvette Cedex, France, DAKO CgA ELISA kit; DAKO A/S, Glostrup, Denmark and CgA; EuroDiagnostica, Malmö, Sweden) reported sensitivity for GEP-NETs to range between 67 and 93\% (specificity $>85 \%$ in all) [38]. A multicenter, prospective study comparing IRMA and ELISA assays found a 36\% discordance rate [39], while an external quality control study identified a 5 -fold inter-laboratory variation rate between IRMA and ELISA results [40]. Differences between CgA levels in plasma and serum have been also reported, with higher levels detected in plasma [41].

\section{Metric Considerations}

Overall, biomarkers are characterized as tools that facilitate diagnosis, disease prognosis, define clinical disease status, predict response to treatment, or indicate the outcome of treatment [33]. An ideal biomarker should possess all these features. The scientific power of a biomarker is defined by its metrics, including sensitivity and specificity. Sensitivity is the ability of a test to correctly classify an individual as "diseased" (positive in disease), while specificity is the ability of a test to correctly classify an individual as disease-free (negative in health) [42]. There is a general agreement that the optimal metrics of NET biomarkers should exceed $90 \%$ for specificity and $80 \%$ for sensitivity, negative predictive value or positive predictive value [43].

\section{GEP-NET Biomarker}

The utility of $\mathrm{CgA}$ in diagnosis, prognosis, and assessment of clinical status in NETs has been investigated for $>3$ decades [44]. The vast majority of studies have examined GEP-NETs, since this group comprises $\sim 2 / 3$ of all NETs. In GEP-NETs that secrete CgA, elevated levels have been correlated with tumor burden, recurrent disease, and poor prognosis or reduced survival [45-47]. A study on 324 pancreatic NETs (PNETs), proposed that CgA levels 3 times above the upper limit of normal (ULN; assay type, ULN not specified, data retrieved from patient charts, and reported as times upper normal limit at the time of diagnosis) as a negative predictor of survival [48], whereas in midgut small intestinal NETs, CgA levels above $5,000 \mu \mathrm{g} / \mathrm{L}$ (ULN $350 \mu \mathrm{g} / \mathrm{L}$, assay type not specified) were considered a poor prognostic [49]. The highest CgA levels are detected in functioning ileal NETs and those with carcinoid syndrome (due to liver metastases; lymph node involvement does not cause a significant elevation in $\mathrm{CgA}$ ) $[46,47]$. The value of $\mathrm{CgA}$ in predicting liver me- 
tastases, compared to CT/MRI is limited (specificity and sensitivity, 50 and 70\%, respectively) [50]. CgA levels are dependent on secretory activity of the tumor, and a decrease in CgA may reflect an antisecretory effect rather than antiproliferative response to treatment [51]. Nonfunctioning tumors may also cause CgA elevation [52]. In gastrinoma, $\mathrm{CgA}$ may be significantly elevated due to stimulation of the gastric enterochromaffin-like cells by gastrin; therefore, CgA should not be used as an universal predictor of metastatic disease or survival [37]. The concept of $\mathrm{CgA}$ as a biomarker of treatment response is based upon the "assumption" that the disease burden correlates with $\mathrm{CgA}$; therefore, effective treatment should reduce disease burden and consequently CgA levels. In clinical trials, the biochemical response to the treatment is often defined as $\geq 50 \%$ reduction of the pretreatment CgA level $[45,46,53]$. The results of the phase III RADIANT-2 clinical trial in advanced NETs proposed that an early decrease of CgA levels while on Everolimus treatment might be used as a surrogate marker of PFS [32]. Similarly, a reduction in $\mathrm{CgA}$ after successful peptide receptor radionuclide therapy (PRRT) [54], or liver transplantation for extensive metastases, has been described [55]. In midgut NETs, CgA has been reported as indicative of recurrence, prior to elevation in the urine of 5-HIAA, or demonstrable radiological changes in tumor size [45]. Recently, a few less enthusiastic about utility of CgA in NETs have been published $[56,57]$. A recent meta-analysis on CgA in GEP-NETs has concluded its usage to be more reliable when monitoring disease progress or response to therapy or recurrence identification, than in the diagnostic setting; and in those with initially impaired values [57].

\section{CgA and the Lung}

In 2011, a panel of 23 German NET experts met in Weimar, to discuss emerging issues in BPNETs. CgA or neuron-specific enolase (NSE) was identified as unsuitable diagnostic biomarkers for BPNETs, with utility proposed for follow-up [58]. In 2014, a Delphic consensus meeting [43] addressing NET biomarkers concluded that current biomarkers for GEP-NETs were inadequate for BPNETs and that there was a key unmet need for the development of BPNET-specific biomarkers [43]. In 2016, the ENETS Advisory Board discussed the unmet needs in PCs, and one of the issue raised was a need for biomarkers with high sensitivity or specificity [59].

Based on this, we sought to evaluate its capability as a diagnostic and prognostic, and whether measurements could be used to predict treatment response or disease recurrence for lung NEN.

\section{Material and Methods}

\section{Literature Search}

We conducted a systematic review to identify all the studies published in PubMed, investigating performance of CgA as a biomarker in lung NEN. The search was undertaken (January 2019) for the terms: ([neuroendocrine tumor OR carcinoid] AND [lung OR pulmonary OR bronchopulmonary OR bronchial]) AND (chromogranin A OR CgA); (small cell lung cancer OR SCLC) AND (chromogranin A OR CgA); ([lung OR pulmonary] AND [large cell neuroendocrine carcinoma OR large cell neuroendocrine cancer]) AND (chromogranin A OR CgA); ([lung OR pulmonary OR bronchopulmonary OR bronchial] AND [neuroendocrine OR carcinoid]) AND (biomarker OR outcome OR survival OR prognosis OR diagnosis) NOT (non-small cell OR squamous OR adenocarcinoma).

Eligibility comprised availability of analysis of circulating CgA in these tumors. Studies that included lung NEN as a part of the larger study cohort but did not present results in these neoplasia per se were excluded. For each term, the search was undertaken without any filter. No language restriction was applied. The reference lists of the included manuscripts were also reviewed to ensure all the relevant studies were enrolled. The recommendations of the preferred reporting items for systematic reviews and meta-analyses statement were followed [60]. The results of the searches are included in the preferred reporting items for systematic reviews and meta-analyses flow diagram (Fig. 1). Overall, 36 studies were included in the final qualitative analysis and 17 in the meta-analysis thereafter.

\section{Data Analysis [61, 62]}

The 36 included studies were examined independently (A.M./ S.M./M.K.) and data extracted (authors, year, type of study, number of patients, controls, true and false positives, true and false negatives) for analysis. Details regarding prognostic, as well as predictive (relapse/treatment response) utility, were also collected. For the meta-analysis, diagnostic accuracy, sensitivity, and specificity were calculated and SEs derived from 95\% CIs. A generic inverse variance method was used to evaluate the effect of the marker. Cochran's Q test and the Higgin's $I^{2}$ test were used to test for study heterogeneity. Both provide an objective evaluation of heterogeneity between studies. Typically, a high $\mathrm{Q}$ test and $I^{2}$ test will be associated with a significant $p$ value $(p<0.05)$ and are representative of significant heterogeneity in a metaanalysis [63]. In these cases, a "random effects" model can then be used to estimate the utility of a biomarker. When the 2 heterogeneity tests are low ( $p$ value $=$ NS), then a fixed effects model can be used to estimate the utility of a biomarker. In this study we have presented the results of random effects models given the heterogeneity in studies and $p$ values and in each assessment have noted which model result is used. A Fisher's exact test (2-tailed) was used to compare CgA-positivity between PC and SCLC. Prism 7.0 for Windows (GraphPad Software, La Jolla, CA, USA, www.graphpad.com) and MedCalc Statistical Software version 16.2.1 (MedCalc Software bvba, Ostend, Belgium; http:// www.medcalc.org; 2017) were utilized. Values are provided as mean $(95 \% \mathrm{CI})$. 


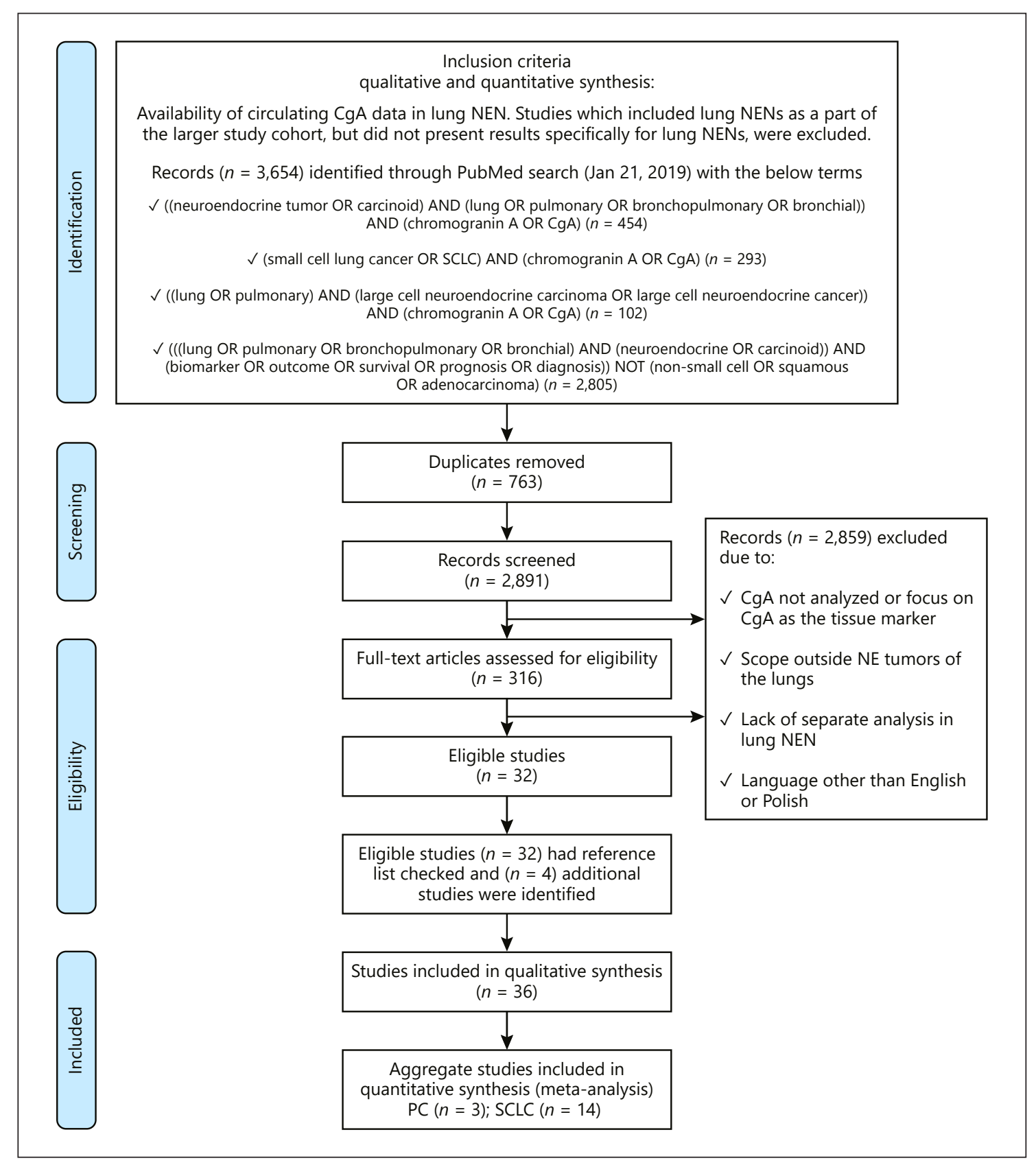

Fig. 1. Preferred reporting items for systematic reviews and meta-analyses flow diagram. NEN, neuroendocrine neoplasia; SCLC, small-cell lung cancer; CgA, chromogranin A; NE, neuroendocrine.

\section{Results}

\section{Literature Search}

As shown in the Flow diagram (Fig. 1), 33 original scientific papers and 3 case reports met the inclusion criteria and were included in the qualitative analysis and 17 original studies (3 in PC, 14 in SCLC) in the meta- analysis thereafter. One study evaluated both PC and SCLC [64]. Detailed characteristics of the included studies are shown in Tables 1-3. Studies included comprised prospective studies $(n=2)$, retrospective studies $(n=31)$, and case reports $(n=3)$. The studies included PC $(n=16)$, SCLC $(n=19)$, and unspecified (NS) lung $\operatorname{NEN}(n=2)$. 


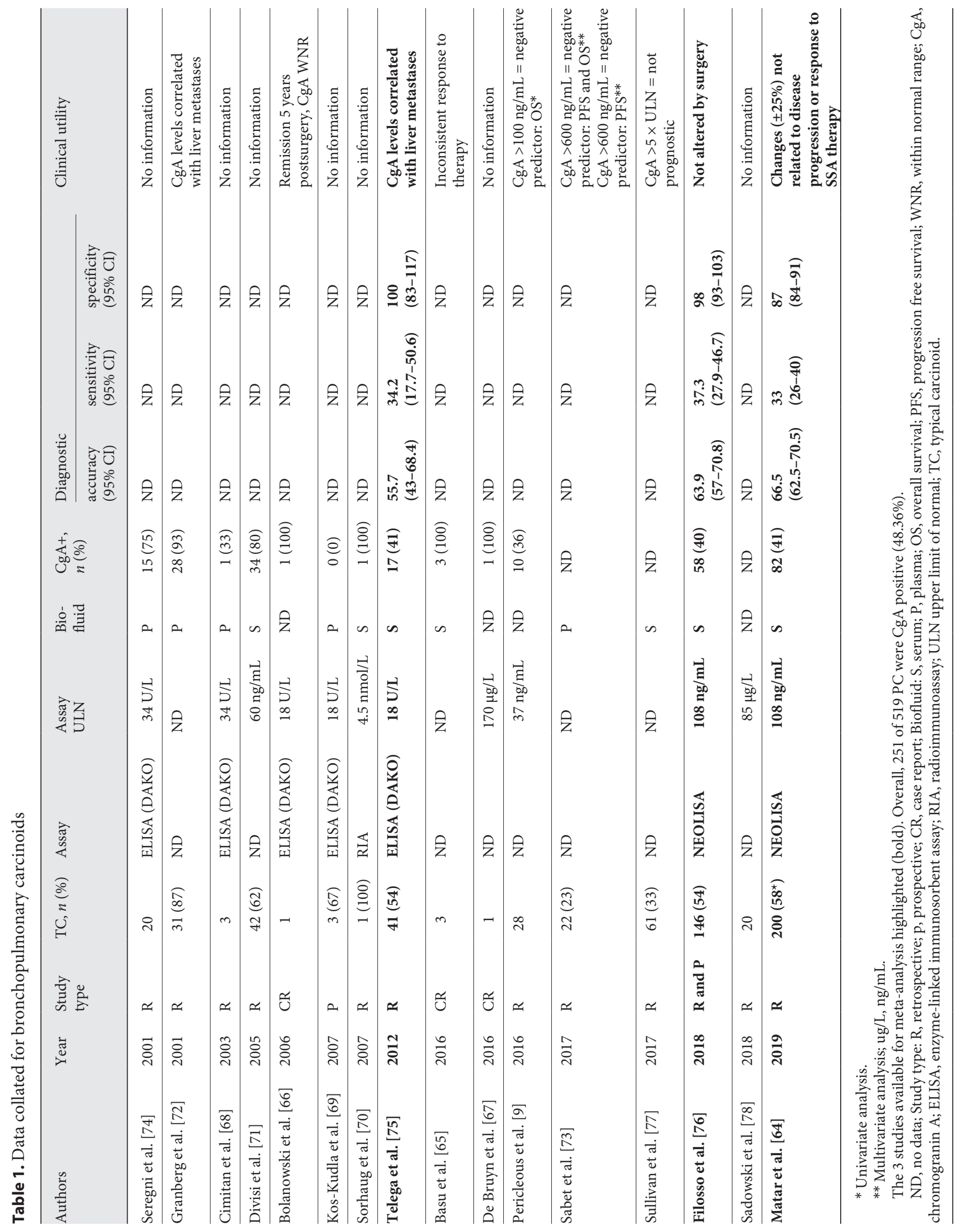




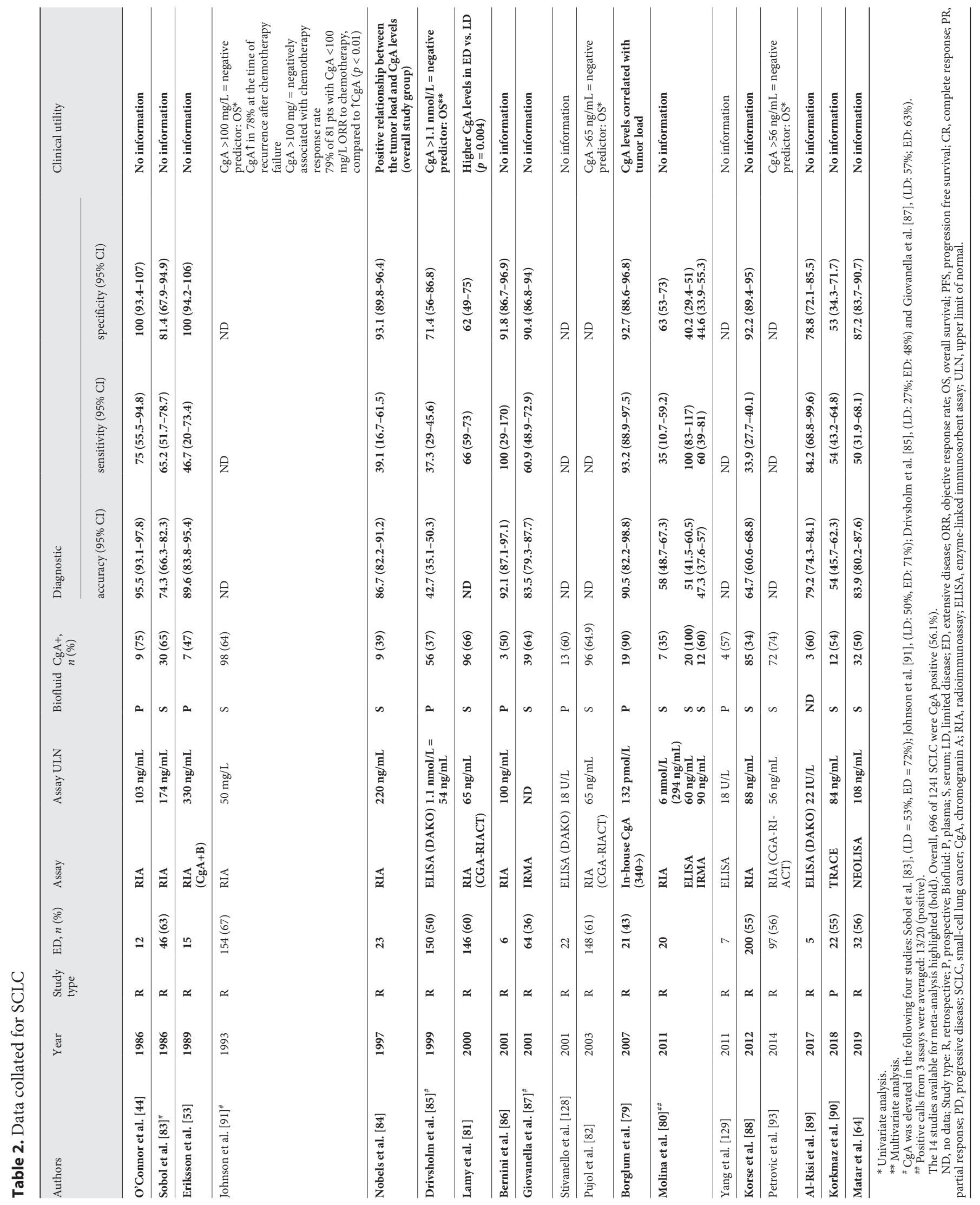




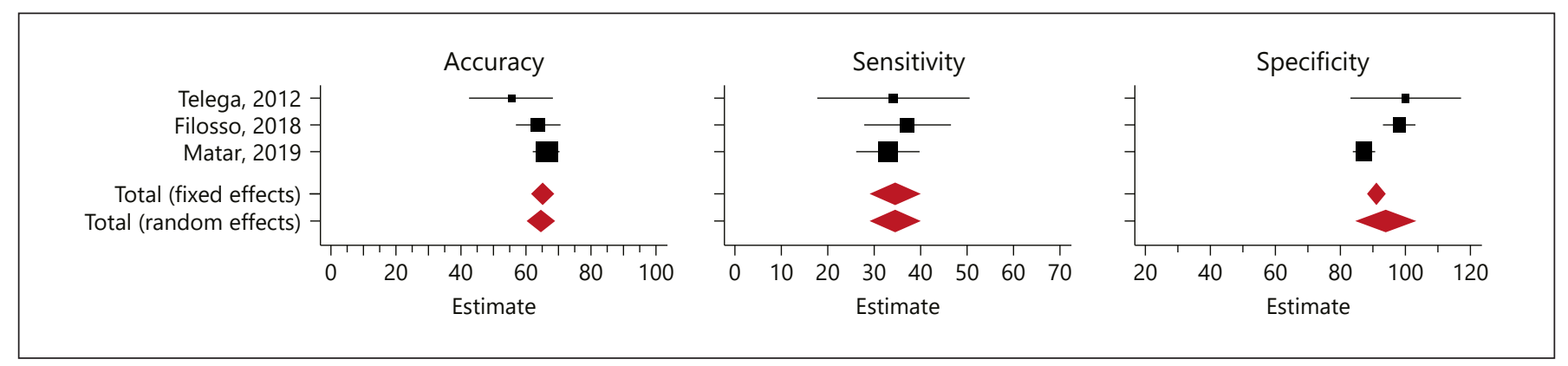

Fig. 2. Diagnostic utility of CgA in PCs using Forest plot assessment. The estimated accuracy and 95\% CIs (black boxes/lines) are presented for accuracy, sensitivity, and specificity in the 3 evaluable studies (Telega et al. [75], Filosso et al. [76], and Matar et al. [64]). The total effects (fixed and random) are presented by red diamonds. The estimated accuracy is $64.5 \pm 2.2(p<0.001)$, sensitivity $34.5 \pm 2.7(p<0.001)$, and specificity $93.8 \pm 4.7(p<0.001)$.

Table 3. Data collated for lung neuroendocrine neoplasia (histological subtype not specified)

\begin{tabular}{|c|c|c|c|c|c|c|c|c|c|c|}
\hline Authors & Year & $\begin{array}{l}\text { Study } \\
\text { type }\end{array}$ & $n$ & Assay & $\begin{array}{l}\text { Assay } \\
\text { ULN }\end{array}$ & $\begin{array}{l}\text { Bio- } \\
\text { fluid }\end{array}$ & $\begin{array}{l}\text { CgA } \\
+n(\%)\end{array}$ & \multicolumn{2}{|l|}{ Diagnostic } & Clinical utility \\
\hline $\begin{array}{l}\text { Lyubimova } \\
\text { et al. [94] }\end{array}$ & 2016 & $\mathrm{R}$ & 41 & $\begin{array}{l}\text { ELISA } \\
(\mathrm{DAKO})\end{array}$ & $33 \mathrm{U} / \mathrm{L}$ & $\mathrm{P}$ & $32(78)$ & 78 & 98 & No information \\
\hline
\end{tabular}

Study type: R, retrospective; P, prospective; Biofluid: P, Plasma; S, Serum; ULN, upper limit of normal; CgA, chromogranin A; RIA, radioimmunoassay; ELISA, enzyme-linked immunosorbent assay.

\section{PCs (TC and AC)}

Sixteen studies which enrolled PC were evaluated [9, 64-78] with numbers ranging from 1 to 200 (median: 21). One study was prospective, the remainder were retrospective. Overall, 251 (48.4\%) of 591 PC exhibited an elevated CgA. Individual sensitivities for the assay were reported to range from 0 [69] to $93 \%$ (in 31 PC [TC: 27, AC: 4], with distant metastases in 97\%) [72] and 2 studies reported specificity ranging between 92 and 94\% [64, 68]. Overall, however, only 3 studies $[64,75,76]$ could be evaluated for further analysis.

A formal meta-analysis identified the diagnostic accuracy (\%) to range between 55.7 (43-68.4) and 66.5 (62.570.5; Table 1; Fig. 2). The overall accuracy was estimated at $64.5 \pm 2.2$. The Q value was 2.7 , and $I^{2}$ was $25.2 \%(p=$ 0.26 ) consistent with modeling homogeneity. A fixed effects model to estimate the accuracy could therefore be used. The diagnostic sensitivity (\%) ranged between 33 (26-40) and 37.3 (27.9-46.7; Table 1; Fig. 2). The overall sensitivity was estimated at $34.5 \pm 2.7$. The $\mathrm{Q}$ value was
0.52 , and $I^{2}$ was $0 \%(p=0.77$; indicating a fixed effect model). The diagnostic specificity (\%) ranged between 87.3 (83.9-90.7) and 100 (82.9-117; Table 1; Fig. 2). The overall specificity was estimated at $93.8 \pm 4.7$. The $\mathrm{Q}$ value was 13.2 and $I^{2}$ was $84.8 \%(p=0.0014)$ consistent with significant model heterogeneity. The estimated specificity for CgA in PC therefore should be considered to have an overall low power and generalizability [63].

Out of the 16 studies, 9 specified PC as either TC or AC but individual numeric data were not available for formal analysis. Higher CgA levels in AC than TC were reported in 2 studies [71, 75], and higher CgA was associated with liver metastases $[72,75]$ but this was not invariant. In a cohort of 41 PC (22 TC, 19 AC) [75], significantly higher $\mathrm{CgA}$ levels were associated with presence of distant metastases $(p=0.003)$, but not primary tumor stage $(\mathrm{T})$ or lymph node involvement. The authors reported CgA levels in localized tumors were within normal range, or were slightly elevated, but were raised in tumors with distant metastasis, especially AC [75]. In a separate study, CgA 


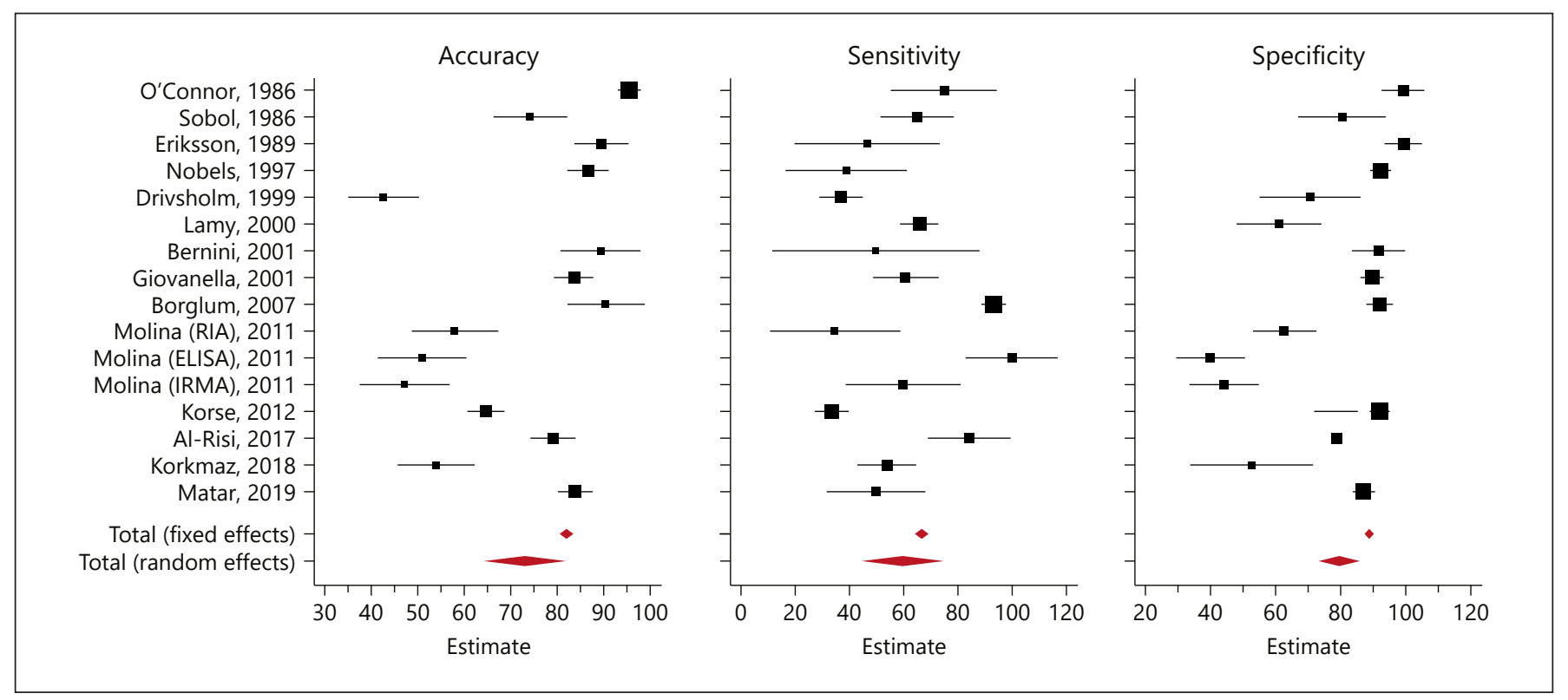

Fig. 3. The diagnostic utility of CgA in SCLC using Forest plot assessment. The estimated accuracy and 95\% CIs (black boxes/lines) are presented for accuracy, sensitivity, and specificity, while the total effects (fixed and random) are presented by red diamonds. Fourteen studies had evaluable data. One study (Molina et al. [80])

levels were only elevated in AC (but not TC) compared to controls but could not be used to differentiate these 2 histological types [64]. Levels were also significantly higher in liver-associated disease compared to those without metastases, but the proportion of patients with elevated levels and stage IV disease was only $43 \%$ [64]. A formal analysis examining localized versus advanced metastatic disease could not be undertaken since individual data for sensitivity and specificity were not available.

The type of CgA assay was identified in 8 studies and the ULN was provided in 12. Five studies utilized the DAKO ELISA CgA assay with ULN within the range 18$34 \mathrm{U} / \mathrm{l}$, and one study - RIA with ULN $4.5 \mathrm{nmol} / \mathrm{L}$. The NEOLISA assay had a ULN of $108 \mathrm{ng} / \mathrm{mL}$. Seven measured CgA in serum, 5 in plasma, and 4 did not specify the biofluid tested (Table 1).

We could not formally evaluate the clinical utility of $\mathrm{CgA}$ in PC as insufficient information was provided in the texts to enable analysis. A review of the studies identified 2 studies which identified that elevated CgA levels were negative predictors of survival in PC. In one PC cohort $(n=28), \mathrm{CgA}>100 \mathrm{ng} / \mathrm{mL}$ was a negative predictor of OS on univariate analysis (ULN $37 \mathrm{ng} / \mathrm{mL}$, assay type not mentioned) [9]. In a second cohort $(n=22), \mathrm{CgA}>600 \mathrm{ng} /$ $\mathrm{mL}$ was a negative predictor of OS, PFS, and PFS after

CgA in Lung NEN: A Meta-Analysis tested 3 separate assays on the same samples. The estimated diagnostic accuracy for CgA was $73 \pm 4(p<0.001)$, sensitivity $59.9 \pm$ $6.9(p<0.001)$, and specificity $79.4 \pm 3(p<0.001)$. ELISA, enzyme linked immunosorbent assay; IRMA, immunoradiometric assay; RIA, radioimmunoassay.

PRRT on multivariate analysis (ULN and assay type not mentioned) [73]. A separate study evaluating the response to ${ }^{177} \mathrm{Lu}$-DOTATATE in $3 \mathrm{PC}$ with extensive bone marrow involvement, reported 4 times decrease of CgA levels $(75,935-17,982 \mu \mathrm{g} / \mathrm{L}, \mathrm{CgA}$ assay type and ULN not mentioned) in PR (partial response) confirmed on imaging, a $\sim 10 \%$ rise of $\mathrm{CgA}(716-797 \mu \mathrm{g} / \mathrm{L})$ in $\mathrm{PD}$ (progressive disease), and $\sim 5$ times rise $(575-2,800 \mu \mathrm{g} / \mathrm{L}$ ) in stable disease (SD) [65]. In the largest study to date $(n=200)$ [64], CgA could not, however, differentiate between those with progressive and those with SD. Moreover, a follow-up analysis of 49 patients for 12 months identified no significant changes in CgA levels irrespective of the patient's clinical status (SD vs. PD) during treatment, or their response to SSA treatment. Of the 27 patients with SD at baseline, 6 patients developed progressive disease during follow-up. Only 2 out of the 6 patients that progressed showed an increase in CgA levels. Changes in CgA levels measured during follow-up were not related to disease progression, failure of treatment, or disease stabilization [64]. The clinical utility of $\mathrm{CgA}$ therefore remains unclear.

\section{Small-Cell Lung Cancer}

Eighteen of the 19 studies were retrospective (Table 2). Study cohorts ranged in size 5-200 (median: 23). All 19 

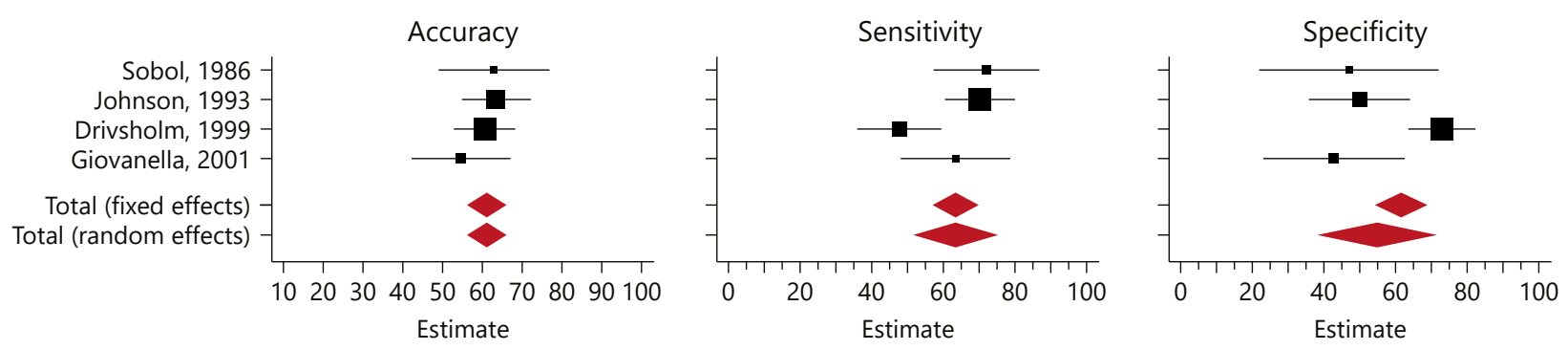

Fig. 4. The diagnostic utility of $\mathrm{CgA}$ in limited versus ED using Forest plot assessment. The estimated accuracy and 95\% CIs (black boxes/lines) are presented for accuracy, sensitivity, and specificity while the total effects (fixed and random) are presented by red diamonds. Four studies (Sobol et al. [83], Johnson et al. [91],
Drivsholm et al. [85], and Giovanella et al. [87]) were evaluable for differentiating extensive from $L D$. The estimated accuracy for differentiating ED was $61 \pm 2.5(p<0.001)$, sensitivity $63.5 \pm 5.9(p<$ $0.001)$, and specificity $54.9 \pm 8.5(p<0.001)$. reported the type of CgA assay and 18, the ULN. Overall, 696 (56.1\%) of 1,241 SCLC patients were positive by CgA. This was significantly higher than in the PC cohort (48.4\%; Fisher's test: $p<0.0001$. Individual diagnostic sensitivities ranged from 33 [79] to $100 \%$ [80] while several studies presented specificities (ranging between 62 and $100 \%)[79,81,82]$. Overall, 14 studies [44, 53, 64, 79-81, 83-90] were evaluable for further analysis.

A formal meta-analysis identified the diagnostic accuracy (\%) to range between $42.7(35.1-50.3)$ and 95.5 (93.1-97.8; Table 2; Fig. 3). The overall accuracy was estimated at $73.0 \pm 4.1$. The Q value was 477 and $I^{2}$ was $97.1 \%(p<0.0001)$ consistent with significant study heterogeneity. The diagnostic sensitivity (\%) ranged between 33.9 (27.7-40) and 100 (83-117; Table 2; Fig. 3). The overall sensitivity was estimated at $59.9 \pm 6.9$. The $\mathrm{Q}$ value was 348 , and $I^{2}$ was $95.7 \%(p<0.0001)$. The diagnostic specificity (\%) ranged between $40.2(29.4-51)$ and 100 (93.4-107; Table 2; Fig. 3). The overall specificity was estimated at $79.4 \pm 3.0$. The $\mathrm{Q}$ value was 258 , and $I^{2}$ was 94.2\% ( $p<0.0001)$ consistent with significant heterogeneity. The high Q values and $I^{2}$ values are indicative that a random effects model was required to estimate biomarker utility. This strongly indicates significant variation in outcomes between the studies and is consistent with the conclusion that CgA is not uniformly useful as a SCLC biomarker.

Four studies identified the sensitivity of $\mathrm{CgA}$ to differentiate limited disease (LD) and extensive disease (ED) in SCLC $[83,85,87,91]$. Disease extent is typically stratified based upon the Veterans Administration Lung cancer group staging system, where LD was defined as disease confined to one hemithorax including the mediastinal lymph nodes and/or the supraclavicular lymph nodes, while ED included the presence of metastases in the contralateral hemithorax and at distant sites [92]. For individual studies, the sensitivity for detecting LD was 17 $67 \%$, while it ranged between 48 and 100\% for ED. Based on higher sensitivity in $\mathrm{ED}$ than in $\mathrm{LD}[79,83,85,91]$, and higher CgA levels in ED [81-83, 85, 93], a positive relationship between CgA levels and tumor burden has been suggested. We formally evaluated whether CgA performed better as a diagnostic in ED than LD (Fig. 4) and identified the following metrics: overall accuracy (random effects model): $61 \pm 2.5$; sensitivity: $63.5 \pm 5.9$, and specificity: $55 \pm 8.5$. All metrics were significantly $(p<$ 0.001) consistent with CgA performing better when the disease was disseminated. However, high Q- and $I^{2}$ results were obtained particularly for sensitivity and specificity. These values indicate that the variability of $\mathrm{CgA}$ as a biomarker to differentiate ED and LD is unsuitable.

In 12 studies, a CgA RIA assay was utilized, ELISA was used in 5, IRMA in 2 studies, TRACE and NEOLISA each in one. Among studies utilizing RIA, the ULN ranged 56$330 \mathrm{ng} / \mathrm{mL}$, for ELISA it was $18-60 \mathrm{ng} / \mathrm{mL}$ and for IRMA: $90 \mathrm{ng} / \mathrm{mL}$ (one study did not mention ULN). Seven studies measured CgA in plasma, 11 in serum and one did not specify the biofluid used. Two studies compared the diagnostic accuracy of CgA assays. In the cohort of 21 SCLC, the processing-independent analysis (CgA PIA/Index test) with trypsin treatment of the plasma samples, followed by $\mathrm{CgA}$ measurement by a previously developed by the study authors RIA specific for the N-terminus of the sequence CgA (340-348), and 3 previously developed RIA specific for CgA (1-9), CgA (250-301), CgA (340348). The CgA PIA and CgA (340-348) assays exhibited 
the highest sensitivity, $76 \%$, and the diagnostic sensitivity for CgA (340-348) assay was significantly higher in ED compared to LD $(p=0.045)$ [79]. In another study $(n=$ 20, SCLC), 3 commercially available CgA assay kits utilizing different methodologies were compared (prefixed $100 \%$ specificity in healthy controls): RIA (ULN, $6 \mathrm{nmol} / \mathrm{L}$ - $294 \mathrm{ng} / \mathrm{mL}$, Euro Diagnostics, Malmö, Sweden), IRMA (90 ng/mL, CIS Bio International, Gif-surYvette, Cedex, France) and ELISA (60 ng/mL, Epitope Diagnostics Inc., San Diego, CA, USA). The ELISA was reported to have reached $100 \%$ sensitivity [80].

We could not formally evaluate the prognostic utility of CgA in SCLC as insufficient data was available. However, in 4 studies elevated CgA levels as a negative predictor of OS; one used multivariate analysis [85], the remainder only univariate analysis $[82,91,93]$. In the cohort of 154 SCLC, rising CgA levels $\geq 10 \%$ (from baseline) were reported as a predictor of relapse in $52 \%$, and CgA levels $>100 \mathrm{mg} / \mathrm{L}$ (RIA, ULN $50 \mathrm{mg} / \mathrm{L}$ ) to be the negative predictor of response to chemotherapy. Seventy-nine percent of 81 SCLC with CgA $<100 \mathrm{mg} / \mathrm{L}$ had an objective response to chemotherapy, compared to patients with CgA levels greater than this. In this study, the majority of patients in whom initial chemotherapy failed exhibited an increase in CgA while on treatment and $78 \%$ had elevated $\mathrm{CgA}$ at the time of recurrence [91]. Overall, $\mathrm{CgA}$ appears to have some anecdotal utility in SCLC but to validate this assertion a formal, prospective evaluation would be required.

\section{Others}

Two studies that did not specify the type of lung NEN were included (Table 3 ). In the cohort of 41 tumors, the sensitivity was $78.1 \%$ and specificity 98.5 (DAKO ELISA, ULN 33U/L, in plasma) [94]. In a second cohort $(n=20)$, the sensitivity was $80 \%$ and specificity was $68 \%$ (IRMA, ULN $100 \mu \mathrm{g} / \mathrm{L}$, in serum).

\section{Discussion}

Overall, the data (metrics) and clinical utility of CgA in lung NEN are scarce, despite that the search was performed without filters and the articles meeting inclusion criteria included a 32-year period (1986-2019). Ninetysix percent of the scientific studies were retrospective. In addition, many studies which involved lung NENs as the component of the larger study cohort had to be excluded, as the CgA metrics, evaluation and analysis, were not presented on these tumors per se. Ten different CgA assay

CgA in Lung NEN: A Meta-Analysis types were utilized, without consistency in the ULN. No assay performed any better than any other assay in terms of metrics.

CgA failed in the precise detection of PC (34\% accurate) and was of limited value in nonmetastasized SCLC $(<50 \%$ accurate). In contrast, distant metastases (or ED), especially in SCLC, were associated with higher CgA levels. However, enthusiasm for this observation is limited by the fact that it was not invariant, as $<75 \%$ had detectable levels. The value of CgA as a biomarker is therefore limited, as the marker fails in disease detection when treatment (surgery) is still potentially curative. About 20 $25 \%$ of SCLC are diagnosed as LD (5-year survival: 15$25 \%$ compared to $<5 \%$ in $\mathrm{ED}$, or median survival of $14-20$ months in LD vs. 7-10 months in ED, respectively [93]).

The clinical utility of $\mathrm{CgA}$ as a biomarker is also difficult to verify. Six studies reported elevated CgA levels to be negatively associated with survival (OS or PFS); however, only 2 were able to confirm those results on multivariate analysis (in PC and SCLC, respectively $[73,85]$ ). Elevated levels of $\mathrm{CgA}$ were also reported as the predictor of relapse in 2 studies (PC and SCLC cohort) [73, 91]. In 2 cohorts, PC and SCLC, elevated CgA levels were identified as potential negative predictors of response to PRRT or chemotherapy, respectively [73, 91]. None of these studies were prospective. None of the studies identified predictive capabilities of $\mathrm{CgA}$ or utility in the assessment of surgical efficacy. A recent study identified no relationship between CgA (either the level of the biomarker or the proportion of patients with detectable $\mathrm{CgA}$ ) and disease progression [64]. These data further compromise the consideration of $\mathrm{CgA}$ as a biomarker of lung $\mathrm{NE}$ disease.

\section{Confounding Factors}

Apart from methodological factors contributing to variations in CgA levels (Table 3), there are physiological, for example, circadian rhythms ( $\mathrm{CgA}$ is a major content of catecholamine storage vesicles, and is released with epinephrine and norepinephrine; circadian rhythms and stress as well as pregnancy [85]) and pathophysiological conditions that have been recognized to affect blood CgA results [14].

As such, there are multiple other causes of elevated blood CgA levels. In clinical practice, the most common reasons are treatment with PPI (proton pump inhibitors) (one of the most widespread drug in use according to the WHO model list of essential medicines: 20th list 2017), atrophic gastritis, or impaired renal function. The majority of positive results is elevated about 2-4 times above the upper range, but in many instances, may reach levels 5-20 
Table 4. Causes of CgA elevation

\begin{tabular}{|c|c|c|}
\hline \multirow[t]{4}{*}{ Systemic disease } & Renal & Renal impairment/failure \\
\hline & Cardiovascular & Hypertension, cardiac insufficiency, heart failure \\
\hline & Inflammatory & $\begin{array}{l}\text { COPD, chronic bronchitis, systemic rheumatoid disease, systemic lupus } \\
\text { erythematosus, systemic inflammatory response syndrome }\end{array}$ \\
\hline & Endocrine & Hyperthyroidism, hyperparathyroidism, hypercortisolism \\
\hline Drugs & \multicolumn{2}{|c|}{ PPI, histamine type-2 receptor inhibitors, corticoids } \\
\hline Physiological factors & \multicolumn{2}{|c|}{ Food ingestion and digestion, strenuous exercise, pregnancy } \\
\hline $\begin{array}{l}\text { Collection artifacts and sam- } \\
\text { ple-related factors }\end{array}$ & \multicolumn{2}{|c|}{$\begin{array}{l}\text { Fibrin presence, hemolysis, lipemia, late afternoon/night > morning, autoantibodies (RF-IgM, Avi- } \\
\text { dine, Heterofile) }\end{array}$} \\
\hline
\end{tabular}

CgA, chromogranin A; PPI, proton pump inhibitors.

times higher than the upper range. In atrophic gastritis or long-term PPI treatment, gastrin levels are elevated by hypochlorhydria. Increased gastrin levels drive the gastric $\mathrm{NE}$ enterochromaffin-like cell to secrete histamine that concomitantly increases CgA in circulation. Withdrawal of this type of treatment for 7 days before performing the assay is not always feasible. In addition, a week may be insufficient, as the longer patients are on PPI, the longer it takes to normalize the CgA levels. In patients with renal impairment, $\mathrm{CgA}$ cannot be cleared from the circulation [29]. Other possible causes of elevated CgA levels are identified in Table 4. Of note, in the current review of studies, significantly higher $\mathrm{CgA}$ concentrations were identified in benign disease (renal failure, heart failure, gastropathy, liver cirrhosis etc.,) than in healthy controls $(p=0.0001)$. Moreover, in one study [80], elevated CgA was identified in $53.1,64.3$, and $68.4 \%$ of benign diseases and $37,59.8$, and $55.4 \%$ of non-NE malignancies without renal failure, using ELISA, IRMA, and RIA, respectively.

False-negative results (i.e., $\operatorname{CgA}$ values fall into the normal range) may be a result of a low secretory or proliferative potential of many carcinoids or due to loss of differentiation (loss of their characteristic structure, along with secretory vesicles [37]) as noted in poorly differentiated tumors. In nonlung NETs, CgA levels are not increased in "benign" NETs, for example, the majority of appendiceal NETs, in $\sim 75 \%$ of insulinomas (increased CgA levels in insulinomas may indicate their malignant character), in duodenal or in rectal NETs [29].

Cutoff use is also relevant and problematic. By way of example, the specificity is defined as the ability of a test to correctly identify those without the disease (Specificity $=$ True Negative/[True Negative + False Positive] $\times$ $100)$. In the cohort of 46 SCLC, a ULN of $174 \mathrm{ng} / \mathrm{mL}$ was established for CgA utilizing a RIA [83]. The healthy controls in this study $(n=20)$ had a mean plasma CgA concentration of $123 \pm 6 \mathrm{ng} / \mathrm{mL}$. Two different SCLC studies [82, 93], utilizing the same RIA identified ULN to be 56 and $65 \mathrm{ng} / \mathrm{mL}$, respectively. The consequences of such variation in cutoffs (lack of standardization) are clear - the 20 healthy controls in [83] would all be false positives.

\section{Other Biomarkers}

Tissue Biomarkers

Diagnosis of a lung NEN is based upon recognition of NE morphology, but also immunohistochemical confirmation of the expression of NE markers, such as CgA, synaptophysin, NCAM (also known as CD56). IHC expression of other markers includes NSE, gastrinreleasing peptide (GRP), or creatinine kinase $\mathrm{BB}[7,95]$. GRP and NCAM are considered as involved in metastatic cascade by autocrine activity or cell-to-cell interaction [95]. In metastasized PC, positive staining of TTF1 may indicate lung or thyroid origin [8]. More importantly, several of those molecules are released into circulation, suggesting possible roles as blood markers (see below).

\section{Circulating Biomarkers}

In SCLC, NSE is currently the most utilized tumor marker. Its sensitivity for diagnosis ranges from 65 to 


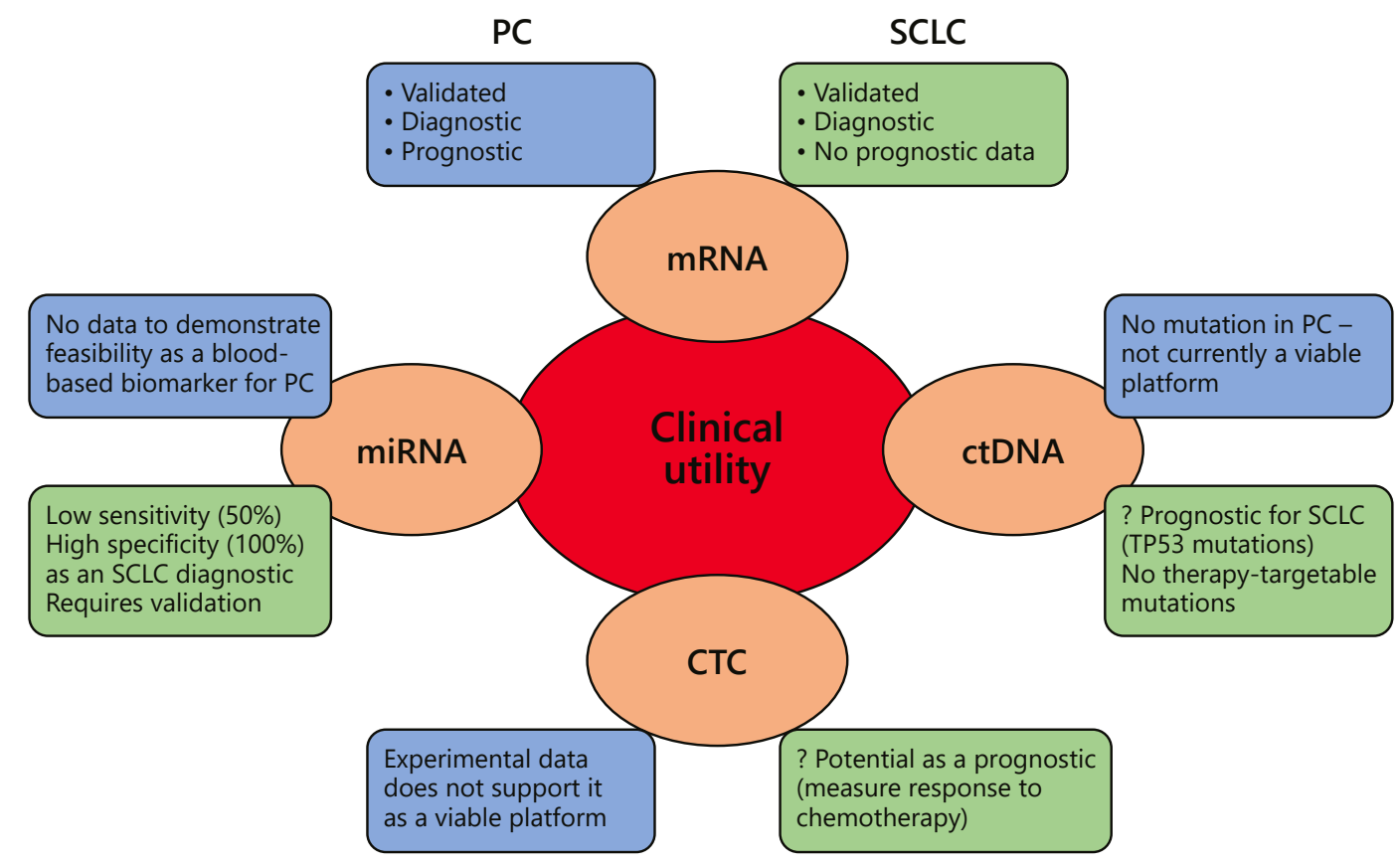

Fig. 5. Current assessment of technical and potential clinical role of novel biomarkers. Four different novel biomarkers are currently available: ctDNA, CTCs, circulating mRNA assays and miRNA. a ctDNA can detect actionable mutations. The absence of any such mutations in PC limits this strategy in this tumor group. In SCLC contrast, the identification of TP53 mutations suggests a role for ctDNA as a prognostic. SCLC however do not express targetable mutations so the use ctDNA as a platform for directing therapy appears restricted. b CTC cannot effectively detect PCs using current methodologies and are not therefore a feasible diagnostic. In SCLC, CTCs can be detected and have utility as a prognostic biomarker in chemotherapy. c Small circulating RNA (miRNA) has not been adequately studied in PC, and there are no data to suggest utility as a

$85 \%[84,91,96]$. NSE has been variously reported as a useful tool for follow-up, prognosis, or prediction of response to therapy $[91,95]$. Although, NSE decreases and increases in SCLC during chemotherapy, the clinical utility of this observation remains controversial [81]. Lactate dehydrogenase is another prognostic biochemical biomarker in SCLC. This is also elevated in various other malignant and nonmalignant conditions, including inflammation [85]. ProGRP has been considered a biomarker for both SCLC and AC [88]. It has been shown to have greater sensitivity than NSE or CgA in SCLC (AUC-ROC 0.95, 0.89, 0.70, respectively; 2-tailed $\mathrm{z}$ test $<$ $0.05)$. The ProGRP level of $53 \mathrm{pg} / \mathrm{mL}$ resulted in the best sensitivity - specificity relationship ( 0.80 sensitivity, 0.96 specificity) [81]. High serum CYFRA 21-1 (>3.6 ng/mL; blood-based biomarker. Preliminary studies in SCLC appear promising but the sensitivity is lower ( $50 \%)$ than CgA or NSE. It is unclear whether the time and resources will be provided to develop these as an adequate biomarker. $\mathbf{d}$ mRNA measurements that can be encompassed within the rubric of multipanel testing provide the best characterized assay. One type of assay, the NETest, simultaneously measures 51 marker genes and uses machine learning algorithms to generate an output. This assay has been demonstrated and independently validated to have utility as an in vitro diagnostic and a prognostic for PC. Such an mRNA approach has been demonstrated as a diagnostic for SCLC. Blue boxes: PC. Green boxes: SCLC. ctDNA, circulating tumor DNA; CTCs, circulating tumor cells; PC, pulmonary carcinoid; SCLC, small-cell lung cancer.

a fragment of cytokeratin subunit 19) along with high serum CgA $(>65 \mathrm{ng} / \mathrm{mL})$, age $>63$ and ECOG $>1$, have been proposed as indicators of poor prognosis in SCLC (CYFRA 21-1: hazard ratio 2.1, 95\% CI 1.4-3.14), in particular in patients receiving cisplatin and etoposidebased chemotherapy (CYFRA 21-1: hazard ratio 2.14, 95\% CI 1.35-3.41) [82].

\section{Novel Biomarkers (Fig. 5)}

\section{Circulating Tumor DNA}

Measurements of circulating tumor DNA have not been performed in PC. PC are not associated with targetable mutations (with exceptions in a minority of cases) so circulating DNA does not seem a viable option for the development of a biomarker [97]. 
In SCLC, mutations in therapeutic targets are rare events (in contrast to lung adenocarcinomas and squamous-cell lung carcinomas). However, tumor suppressor TP53 is mutated in $>90 \%$ of SCLC [98] and TP53 mutations are an early event in tumorigenesis [99]. A recent study evaluated the utility of identifying TP53 mutation in the cfDNA in SCLC. Fifty-one SCLC and 123 noncancer controls were enrolled. TP53 mutations were detected in the cfDNA of $49 \%$ SCLC and $11.4 \%$ of noncancer controls. The accuracy of this approach was $78 \%$, but the sensitivity was only $49 \%$. The common detection of somatic mutations in controls significantly limits the use of detecting TP53 mutations in ctDNA as a screening tool [99].

\section{Circulating Tumor Cells}

One study assessed the utility of CTC in predicting radiological progression in NETs, including 13 metastatic PC in the study cohort [100]. The platform for CTC detection requires expression of EpCAM to detect the circulating tumor cells. In the PC subset, the EpCAM expression was variable, which identified to the authors that this approach was not feasible.

In SCLC, CTCs are under investigation as prognostic markers of survival, or predictors of response to chemotherapy, especially cisplatin based [101, 102]. Recently published, in the cohort of 42 SCLC, CTCs detection was performed prior and post the first cycle of chemotherapy. CTC was positive $(\geq 2)$ in $76.2 \%$ of SCLC and negative in the control group. In patients with $\geq 2$ and $<2$ CTCs/7.5 $\mathrm{mL}$ of blood: at baseline sampling, PFS was 6 and 10.7 months, while post-chemotherapy, PFS was 4.9 and 10.5 months, respectively, showing that baseline CTC numbers and the change in CTC numbers after 1 cycle of chemotherapy may be prognostic factors of PFS in SCLC [102].

\section{Multianalyte Gene Transcripts Analysis}

Transcriptional profiling of tumor tissue has identified a series of NE transcripts that are detectable in the circulation [103] and can be used clinically to evaluate GEP-NETs [104-110], paragangliomas and pheochromocytomas [111], and lung NEN [112]. This wholeblood-based multianalyte transcript (mRNA) analysis the NETest - is the most extensively investigated circulating molecular biomarker tool [103-109, 113-115]. A recent large NIH-funded study of gene expression data from 10,224 samples from 32 different tumor types, independently confirmed, the biological basis of the NET signature. This categorically demonstrated that the NETest genes capture a NEN phenotype [116].
Two studies have demonstrated that NETest gene expression levels were highly correlated between lung NE tumor tissue and matched blood. In the first study, the Pearson R ranged 0.63-0.91, $p<0.001)$ [117]; and in the second, the Pearson R for PC was $0.82(p<0.0001)$ while it was 0.68 for SCLC $(p<0.0001)$ [112]. In 2 independent cohorts, the assay was effective as a diagnostic: sensitivity $92-93 \%$, specificity $89-100 \%[112,117]$. The test can also define the completeness of surgical resection (area under the curve: 0.98) [76], predict the response to treatment (PRRT) [109], and be used to monitor the efficacy of current therapies including somatostatin analogs [112]. Comparison assessment with other biomarkers has demonstrated that the NETest significantly out-performs monoanalyte-based assays and is superior for detection and disease management $[103,110,118]$.

\section{Circulating miRNAs}

Circulating miRNA signatures have been proposed for GEP-NETs, for example, in small bowel NETs $[119,120]$, but nothing has been identified for PC. At a tissue level, miRNA expression has been reported to differentiate PC from SCLC/LCNEC [121], but it is unclear whether this will translate to clinical utility.

In SCLC, $n=50$, plasma miR-92a-2 has been proposed for SCLC diagnosis, obtained metrics were: sensitivity 56 , specificity 100\%, AUC-ROC 0.76 [122], while its overexpression in tumor tissue (FFPE, $n=34$ ) has been associated with chemoresistance and decreased survival [123]. A panel of 10 plasma miRNAs, identified initially in a preclinical model, miR-95, -141, -200a, -200b, -200c, -210, -335\#, $-375,-429)$, was found consistently elevated in SCLC $(n=$ 16) [124]. In another SCLC cohort, $n=72$, LD: 22, ED: 50, 7 miRNAs have been identified as differentially expressed between LD versus ED (miR-574-5p, miR-874, miR-3074$5 p$, miR-4685-5p, and miR-4746-3p were overexpressed, whereas miR-184 and miR-4459 were downregulated. MiR-574-5p was found as an independent prognostic factor for SCLC [125]. Circulating miRNA urgently requires standardization and optimization [126]; therefore, the clinical utility of such signatures remains to be determined.

\section{Coda}

Based upon rigorous assessment and meta-analysis of the published data, $\mathrm{CgA}$ has been shown to exhibit major limitations as a consistently effective and accurate biomarker for lung NEN, especially carcinoids. The results of this systematic review and meta-analysis accord with 
recent consensus publications that conclude that $\mathrm{CgA}$ is an inadequate diagnostic since it only detects $34 \%$ of PCs - and is especially limited in the detection of localized disease. There appears to be some utility for $\mathrm{CgA}$ in the detection of advanced disease (with liver metastases), particularly in SCLC, but the metrics, even for ED do not meet minimal NIH criteria of $80 \%$ [127]. A further significant concern is that in the SCLC cohort, the high Q value $/ I^{2}$ test results identify that the biomarker exhibits significant variability. Of note is the analytic observation that this is not related to the type of assay used, although different assays in the same patient cohort ranged in diagnostic sensitivity from 35 to $100 \%$.

Anecdotal evidence suggests that there may be a role for $\mathrm{CgA}$ in the prediction of disease relapse or response to treatment in a subcohort of SCLC patients (those that express elevated levels). Its prognostic value, however, remains to be determined. This will require validated, wellconstructed, multicenter, prospective, randomized stud- ies. Given the preponderance of negative information regarding the clinical utility of $\mathrm{CgA}$, there is an emerging need for a new class of novel biomarkers. In particular, at this time multianalyte biomarkers that facilitate diagnosis, predict survival, and assess treatment efficacy in lung NENs seem viable candidates for further clinical consideration. Of all current novel markers, measurements of multianalyte transcript analysis appear to represent the most promising strategy in bronchopulmonary NET disease [43].

\section{Disclosure Statement}

There are no conflicts of interest that could be perceived as prejudicing the impartiality of the research reported. Wren Laboratories undertakes biomarker analysis including the NETest and CgA (EuroDiagnostics). Wren Laboratories is a clinically accredited testing facility that has approval for evaluating these biomarkers in patients with NETs.

\section{References}

1 Pelosi G, Sonzogni A, Harari S, Albini A, Bresaola E, Marchiò C, et al. Classification of pulmonary neuroendocrine tumors: new insights. Transl Lung Cancer Res. 2017 Oct; 6(5):513-29.

2 International Agency for Research on Cancer. Travis WD, Brambilla E, Burke A, Marx A, Nicholson AG, editors. Who classification of tumours of the lung, pleura, thymus and heart. 4th Edition.

3 Gustafsson BI, Kidd M, Chan A, Malfertheiner MV, Modlin IM. Bronchopulmonary neuroendocrine tumors. Cancer. 2008 Jul;113(1): 5-21.

4 Rekhtman N. Neuroendocrine tumors of the lung: an update. Arch Pathol Lab Med. 2010 Nov;134(11):1628-38.

5 Gustafsson BI, Kidd M, Modlin IM. Neuroendocrine tumors of the diffuse neuroendocrine system. Curr Opin Oncol. 2008 Jan;20(1):1-12.

6 Pelosi G, Bianchi F, Hofman P, Pattini L, Ströbel $\mathrm{P}$, Calabrese F, et al. Recent advances in the molecular landscape of lung neuroendocrine tumors. Expert Rev Mol Diagn. 2019 Apr;19(4):281-97.

7 Travis WD, Brambilla E, Nicholson AG, Yatabe Y, Austin JH, Beasley MB, et al.; WHO Panel. The 2015 world health organization classification of lung tumors: impact of genetic, clinical and radiologic advances since the 2004 classification. J Thorac Oncol. 2015 Sep; 10(9):1243-60.

8 Caplin ME, Baudin E, Ferolla P, Filosso P, Garcia-Yuste M, Lim E, et al.; ENETS consensus conference participants. Pulmonary neuroendocrine (carcinoid) tumors: europe- an Neuroendocrine Tumor Society expert consensus and recommendations for best practice for typical and atypical pulmonary carcinoids. Ann Oncol. 2015 Aug;26(8): 1604-20.

9 Pericleous M, Karpathakis A, Toumpanakis C, Lumgair H, Reiner J, Marelli L, et al. Welldifferentiated bronchial neuroendocrine tumors: clinical management and outcomes in 105 patients. Clin Respir J. 2018 Mar;12(3): 904-14.

10 Filosso PL, Rena O, Donati G, Casadio C, Ruffini E, Papalia E, et al. Bronchial carcinoid tumors: surgical management and long-term outcome. J Thorac Cardiovasc Surg. 2002 Feb; 123(2):303-9.

11 Hendifar AE, Marchevsky AM, Tuli R. Neuroendocrine tumors of the lung: current challenges and advances in the diagnosis and management of well-differentiated disease. J Thorac Oncol. 2017 Mar;12(3):42536.

12 de Laat JM, Pieterman CR, van den Broek MF, Twisk JW, Hermus AR, Dekkers OM, et al. Natural course and survival of neuroendocrine tumors of thymus and lung in MEN1 patients. J Clin Endocrinol Metab. 2014 Sep; 99(9):3325-33

13 Chong S, Lee KS, Chung MJ, Han J, Kwon OJ, Kim TS. Neuroendocrine tumors of the lung: clinical, pathologic, and imaging findings. Radiographics. 2006 Jan-Feb;26(1):41-57; discussion 57-8.

14 Modlin IM, Gustafsson BI, Moss SF, Pavel M, Tsolakis AV, Kidd M. Chromogranin A-biological function and clinical utility in neuro endocrine tumor disease. Ann Surg Oncol. 2010 Sep;17(9):2427-43.

15 Nobels FR, Kwekkeboom DJ, Bouillon R, Lamberts SW. Chromogranin A: its clinical value as marker of neuroendocrine tumours. Eur J Clin Invest. 1998 Jun;28(6):431-40.

16 Troger J, Theurl M, Kirchmair R, Pasqua T, Tota B, Angelone T, et al. Granin-derived peptides. Prog Neurobiol. 2017 Jul;154:37-61.

17 Bensch KG, Corrin B, Pariente R, Spencer H. Oat-cell carcinoma of the lung. Its origin and relationship to bronchial carcinoid. Cancer. 1968 Dec;22(6):1163-72

18 Williams ED, Sandler M. The classification of carcinoid tum ours. Lancet. 1963 Feb;1(7275): 238-9.

19 Sutherland KD, Berns A. Cell of origin of lung cancer. Mol Oncol. 2010 Oct;4(5):397-403.

20 Smalley M, Ashworth A. Stem cells and breast cancer: A field in transit. Nat Rev Cancer. 2003 Nov;3(11):832-44.

21 Blank A, Schmitt A, Perren A. Pathology: classification and Immunoprofile. Front Horm Res. 2015;44:104-14.

22 Schnabel PA, Junker K. [Pulmonary neuroendocrine tumors in the new WHO 2015 classification: start of breaking new grounds?]. Pathologe. 2015 May;36(3):283-92.

23 Rindi G, Klersy C, Inzani F, Fellegara G, Ampollini L, Ardizzoni A, et al. Grading the neuroendocrine tumors of the lung: an evidencebased proposal. Endocr Relat Cancer. 2013 Dec;21(1):1-16.

24 Volante M, Gatti G, Papotti M. Classification of lung neuroendocrine tumors: lights and shadows. Endocrine. 2015 Nov;50(2):315-9. 
25 Deftos LJ. Chromogranin A: its role in endocrine function and as an endocrine and neuroendocrine tumor marker. Endocr Rev. 1991 May;12(2):181-7.

26 Blaschko H, Comline RS, Schneider FH, Silver M, Smith AD. Secretion of a chromaffin granule protein, chromogranin, from the adrenal gland after splanchnic stimulation. Nature. 1967 Jul;215(5096):58-9.

27 Kasprzak A, Zabel M, Biczysko W. Selected markers (chromogranin a, neuron-specific enolase, synaptophysin, protein gene product 9.5) in diagnosis and prognosis of neuroendocrine pulmonary tumours. Pol J Pathol. 2007; 58(1):23-33.

28 D'amico MA, Ghinassi B, Izzicupo P, Manzoli L, Di Baldassarre A. Biological function and clinical relevance of chromogranin A and derived peptides. Endocr Connect. 2014 Apr; $3(2): R 45-54$.

29 Ardill JE, O'Dorisio TM. Circulating biomarkers in neuroendocrine tumors of the enteropancreatic tract: application to diagnosis, monitoring disease, and as prognostic indicators. Endocrinol Metab Clin North Am. 2010 Dec;39(4):777-90.

30 Duque M, Modlin IM, Gupta A, Saif MW. Biomarkers in neuroendocrine tumors. JOP. 2013 Jul 10;14(4):372-6.

31 Eriksson B, Oberg K. Peptide hormones as tumor markers in neuroendocrine gastrointestinal tumors. Acta Oncol. 1991;30(4):47783.

32 Gkolfinopoulos S, Tsapakidis K, Papadimitriou K, Papamichael D, Kountourakis P. Chromogranin A as a valid marker in oncology: clinical application or false hopes? World J Methodol. 2017 Mar;7(1):9-15.

33 Modlin IM, Oberg K, Taylor A, Drozdov I, Bodei L, Kidd M. Neuroendocrine tumor biomarkers: Current status and perspectives. Neuroendocrinology. 2014;100(4): 265-77.

34 Campana D, Nori F, Piscitelli L, Morselli-Labate AM, Pezzilli R, Corinaldesi R, et al. Chromogranin A: is it a useful marker of neuroendocrine tumors? J Clin Oncol. 2007 May; 25(15):1967-73.

35 Marotta V, Zatelli MC, Sciammarella C, Ambrosio MR, Bondanelli M, Colao A, et al. Chromogranin A as circulating marker for diagnosis and management of neuroendocrine neoplasms: more flaws than fame. Endocr Relat Cancer. 2018 Jan;25(1):R1129.

36 Oberg K, Couvelard A, Delle Fave G, Gross D, Grossman A, Jensen RT, et al.; Antibes Consensus Conference participants. Enets consensus guidelines for standard of care in neuroendocrine tumours: biochemical markers. Neuroendocrinology. 2017;105(3):201-11.

37 Gut P, Czarnywojtek A, Fischbach J, Baczyk M, Ziemnicka K, Wrotkowska E, et al. Chromogranin a - unspecific neuroendocrine marker. Clinical utility and potential diagnostic pitfalls. Archives of medical science. Arch Med Sci. 2016 Feb 1;12(1):1-9.
38 Stridsberg M, Eriksson B, Oberg K, Janson ET. A comparison between three commercial kits for chromogranin A measurements. J Endocrinol. 2003 May;177(2):337-41.

39 Leon A, Torta M, Dittadi R. degli Uberti E, Ambrosio MR, Delle Fave G, De Braud F, Tomassetti P, Gion M, Dogliotti L. Comparison between two methods in the determination of circulating chromogranin a in neuroendocrine tumors (NETs): Results of a prospective multicenter observational study. Int J Biol Markers. 2005 Jul-Sep;20: 156-68.

40 Verderio P, Dittadi R, Marubini E, Pizzamiglio S, Gion M, De Apollonia L, et al.; Italian Network for Quality Assessment of Tumor Biomarkers (INQAT) Group. An Italian program of External Quality Control for chromogranin $\mathrm{A}(\mathrm{CgA})$ assay: performance evaluation of CgA determination. Clin Chem Lab Med. 2007;45(9):1244-50.

41 Glinicki P, Kapuścińska R, Jeske W. The differences in chromogranin A ( $\mathrm{CgA})$ concentrations measured in serum and in plasma by IRMA and ELISA methods. Endokrynol Pol. 2010 Jul-Aug;61(4):346-50.

42 Parikh R, Mathai A, Parikh S, Chandra Sekhar G, Thomas R. Understanding and using sensitivity, specificity and predictive values. Indian J Ophthalmol. 2008 Jan-Feb;56(1):4550.

43 Oberg K, Modlin IM, De Herder W, Pavel M, Klimstra D, Frilling A, et al. Consensus on biomarkers for neuroendocrine tumour disease. Lancet Oncol. 2015 Sep;16(9):e435-46.

44 O'Connor DT, Deftos LJ. Secretion of chromogranin A by peptide-producing endocrine neoplasms. N Engl J Med. 1986 May;314(18): 1145-51.

45 Welin S, Stridsberg M, Cunningham J, Granberg D, Skogseid B, Oberg K, et al. Elevated plasma chromogranin a is the first indication of recurrence in radically operated midgut carcinoid tumors. Neuroendocrinology. 2009;89(3):302-7.

46 Arnold R, Wilke A, Rinke A, Mayer C, Kann $\mathrm{PH}, \mathrm{Klose} \mathrm{KJ}$, et al. Plasma chromogranin a as marker for survival in patients with metastatic endocrine gastroenteropancreatic tumors. Clin Gastroenterol Hepatol. 2008 Jul;6(7): $820-7$.

47 Ardill JE, Erikkson B. The importance of the measurement of circulating markers in patients with neuroendocrine tumours of the pancreas and gut. Endocr Relat Cancer. 2003 Dec;10(4):459-62.

48 Ekeblad S, Skogseid B, Dunder K, Oberg K, Eriksson B. Prognostic factors and survival in 324 patients with pancreatic endocrine tumor treated at a single institution. Clin Cancer Res. 2008 Dec 1;14(23):7798-803.

49 Janson ET, Holmberg L, Stridsberg M, Eriksson B, Theodorsson E, Wilander E, et al. Carcinoid tumors: analysis of prognostic factors and survival in 301 patients from a referral center. Ann Oncol. 1997 Jul;8(7): 685-90.
50 Vezzosi D, Walter T, Laplanche A, Raoul JL, Dromain C, Ruszniewski P, et al. Chromogranin A measurement in metastatic welldifferentiated gastroenteropancreatic neuroendocrine carcinoma: screening for false positives and a prospective follow-up study. Int J Biol Markers. 2011 Apr-Jun;26(2):94101.

51 Baudin E, Bidart JM, Bachelot A, Ducreux M, Elias D, Ruffié P, et al. Impact of chromogranin A measurement in the work-up of neuroendocrine tumors. Ann Oncol. 2001; 12(Suppl 2):S79-82.

52 Peracchi M, Conte D, Gebbia C, Penati C, Pizzinelli S, Arosio M, et al. Plasma chromogranin $\mathrm{A}$ in patients with sporadic gastro-entero-pancreatic neuroendocrine tumors or multiple endocrine neoplasia type 1. Eur J Endocrinol. 2003 Jan;148(1):39-43.

53 Eriksson B, Arnberg H, Oberg K, Hellman U, Lundqvist G, Wernstedt C, et al. Chromogranins-new sensitive markers for neuroendocrine tumors. Acta Oncol. 1989; 28(3):325-9.

54 Kwekkeboom DJ, Teunissen JJ, Bakker WH, Kooij PP, de Herder WW, Feelders RA, et al. Radiolabeled somatostatin analog [177LuDOTA0,Tyr3] octreotate in patients with endocrine gastroenteropancreatic tumors. J Clin Oncol. 2005 Apr;23(12):2754-62.

55 Olausson M, Friman S, Herlenius G, Cahlin C, Nilsson O, Jansson S, et al. Orthotopic liver or multivisceral transplantation as treatment of metastatic neuroendocrine tumors. Liver Transpl. 2007 Mar;13(3):32733.

56 Pulvirenti A, Rao D, McIntyre CA, Gonen M, Tang LH, Klimstra DS, et al. Limited role of chromogranin a as clinical biomarker for pancreatic neuroendocrine tumors. HPB (Oxford). 2019 May;21(5):612-8.

57 Rossi RE, Ciafardini C, Sciola V, Conte D, Massironi S. Chromogranin a in the followup of gastroenteropancreatic neuroendocrine neoplasms: is it really game over? A systematic review and meta-analysis. Pancreas. 2018 Nov/Dec;47(10):1249-55.

58 Hörsch D, Schmid KW, Anlauf M, Darwiche K, Denecke T, Baum RP, et al. Neuroendocrine tumors of the bronchopulmonary system (typical and atypical carcinoid tumors): current strategies in diagnosis and treatment. Conclusions of an expert meeting February 2011 in Weimar, Germany. Oncol Res Treat. 2014;37(5):266-76.

59 Baudin E, Hayes AR, Scoazec JY, Filosso PL, Lim E, Kaltsas G, et al.; ENETS 2016 Munich Advisory Board Participants; ENETS 2016 Munich Advisory Board Participants. Unmet medical needs in pulmonary neuroendocrine (carcinoid) neoplasms. Neuroendocrinology. 2019;108(1):7-17.

60 Moher D, Liberati A, Tetzlaff J, Altman DG; PRISMA Group. Preferred reporting items for systematic reviews and meta-analyses: the PRISMA statement. BMJ. 2009 Jul;339 jul21 1:b2535. 
61 Yang X, Yang Y, Li Z, Cheng C, Yang T, Wang $\mathrm{C}$, et al. Diagnostic value of circulating chromogranin a for neuroendocrine tumors: a systematic review and meta-analysis. PLoS One. 2015 Apr;10(4):e0124884.

62 Gao Y, Gao H, Wang G, Yin L, Xu W, Peng Y, et al. A meta-analysis of Prognostic factor of Pancreatic neuroendocrine neoplasms. Sci Rep. 2018 May;8(1):7271.

63 Higgins JP, Thompson SG, Deeks JJ, Altman DG. Measuring inconsistency in meta-analyses. BMJ. 2003 Sep;327(7414):557-60.

64 Matar S, Malczewska A, Oberg K, Bodei L, Aslanian $\mathrm{H}$, Lewczuk-Myślicka $\mathrm{A}$, et al. Blood chromogranin a is not effective as a biomarker for diagnosis or management of bronchopulmonary carcinoids. Neuroendocrinology. 2019, Epub ahead of print.

65 Basu S, Ranade R, Thapa P. Metastatic neuroendocrine tumor with extensive bone marrow involvement at diagnosis: evaluation of response and hematological toxicity profile of prrt with (177)lu-dotatate. World J Nucl Med. 2016 Jan-Apr;15(1):38-43.

66 Bolanowski M, Kos-Kudła B, Rzeszutko M, Marciniak M, Zatońska K. [Five year remission of GHRH secreting bronchial neuroendocrine tumor with symptoms of acromegaly. Utility of chromogranin $\mathrm{A}$ in the monitoring of the disease]. Endokrynol Pol. 2006 Jan-Feb;57(1):32-6

67 De Bruyn D, Lamont J, Vanderstraeten E, Van Belle S, Platteau E, De Zaeytijd J, et al. Bilateral choroidal metastases from endobronchial carcinoid treated with somatostatin analogues. Open Ophthalmol J. 2016 Sep;10(1):160-5.

68 Cimitan M, Buonadonna A, Cannizzaro R, Canzonieri V, Borsatti E, Ruffo R, et al. Somatostatin receptor scintigraphy versus chromogranin $\mathrm{A}$ assay in the management of patients with neuroendocrine tumors of different types: clinical role. Ann Oncol. 2003 Jul;14(7):1135-41

69 Kos-Kudła B, Zemczak A, Foltyn W, Marek B, Strzelczyk J, Telega A, et al. Octreotide suppression test in diagnosing and predicting the outcome of therapy in patients with neuroendocrine tumors. Preliminary report. Endokrynol Pol. 2007 Mar-Apr;58(2):123-9.

70 Sorhaug S, Steinshamn S, Haaverstad R, Nordrum IS, Martinsen TC, Waldum HL. Expression of neuroendocrine markers in non-small cell lung cancer. APMIS. 2007 Feb;115(2): 152-63.

71 Divisi D, Crisci R. Carcinoid tumors of the lung and multimodal therapy. Thorac Cardiovasc Surg. 2005 Jun;53(3):168-72.

72 Granberg D, Eriksson B, Wilander E, Grimfjärd P, Fjällskog ML, Oberg K, et al. Experience in treatment of metastatic pulmonary carcinoid tumors. Ann Oncol. 2001 Oct; 12(10):1383-91.

73 Sabet A, Haug AR, Eiden C, Auernhammer CJ, Simon B, Bartenstein P, et al. Efficacy of peptide receptor radionuclide therapy with $177 \mathrm{Lu}$-octreotate in metastatic pulmonary neuroendocrine tumors: a dual-centre analysis. Am J Nucl Med Mol Imaging. 2017 Apr; $7(2): 74-83$
74 Seregni E, Ferrari L, Bajetta E, Martinetti A, Bombardieri E. Clinical significance of blood chromogranin A measurement in neuroendocrine tumours. Ann Oncol. 2001;12(Suppl 2):S69-72.

75 Telega A, Kos-Kudła B, Foltyn W, BlicharzDorniak J, Rosiek V. Selected neuroendocrine tumour markers, growth factors and their receptors in typical and atypical bronchopulmonary carcinoids. Endokrynol Pol. 2012; 63(6):477-82

76 Filosso PL, Kidd M, Roffinella M, Lewczuk A Chung KM, Kolasinska-Cwikla A, et al. The utility of blood neuroendocrine gene transcript measurement in the diagnosis of bronchopulmonary neuroendocrine tumours and as a tool to evaluate surgical resection and disease progression. Eur J Cardiothorac Surg. 2018 Mar;53(3):631-9.

77 Sullivan I, Le Teuff G, Guigay J, Caramella C, Berdelou A, Leboulleux S, et al. Antitumour activity of somatostatin analogues in sporadic, progressive, metastatic pulmonary carcinoids. Eur J Cancer. 2017 Apr;75:259-67.

78 Sadowski SM, Christ E, Bédat B, Kollár A, Karenovics W, Perren A, et al.; SwissNET registry. Nationwide multicenter study on the management of pulmonary neuroendocrine (carcinoid) tumors. Endocr Connect. 2018 Jan;7(1):8-15.

79 Børglum T, Rehfeld JF, Drivsholm LB, Hilsted L. Processing-independent quantitation of chromogranin a in plasma from patients with neuroendocrine tumors and small-cell lung carcinomas. Clin Chem. 2007 Mar;53(3):438-46.

80 Molina R, Alvarez E, Aniel-Quiroga A, Borque M, Candás B, Leon A, et al. Evaluation of chromogranin A determined by three different procedures in patients with benign diseases, neuroendocrine tumors and other malignancies. Tumour Biol. 2011 Feb;32(1):13-22.

81 Lamy PJ, Grenier J, Kramar A, Pujol JL. Progastrin-releasing peptide, neuron specific enolase and chromogranin A as serum markers of small cell lung cancer. Lung Cancer. 2000 Sep;29(3):197-203.

82 Pujol JL, Quantin X, Jacot W, Boher JM, Grenier J, Lamy PJ. Neuroendocrine and cytokeratin serum markers as prognostic determinants of small cell lung cancer. Lung Cancer. $2003 \mathrm{Feb} ; 39(2): 131-8$

83 Sobol RE, O'Connor DT, Addison J, Suchocki K, Royston I, Deftos LJ. Elevated serum chromogranin A concentrations in small-cell lung carcinoma. Ann Intern Med. 1986 Nov; 105(5):698-700.

84 Nobels FR, Kwekkeboom DJ, Coopmans W, Schoenmakers CH, Lindemans J, De Herder WW, et al. Chromogranin A as serum marker for neuroendocrine neoplasia: comparison with neuron-specific enolase and the alphasubunit of glycoprotein hormones. J Clin Endocrinol Metab. 1997 Aug;82(8):2622-8.

85 Drivsholm L, Paloheimo LI, Osterlind K. Chromogranin A, a significant prognostic factor in small cell lung cancer. Br J Cancer. 1999 Oct;81(4):667-71.
86 Bernini GP, Moretti A, Ferdeghini M, Ricci S, Letizia C, D'Erasmo E, et al. A new human chromogranin ' $A$ ' immunoradiometric assay for the diagnosis of neuroendocrine tumours. Br J Cancer. 2001 Mar;84(5):636-42.

87 Giovanella L, Ceriani L, Bandera M, Garancini S. Immunoradiometric assay of chromogranin A in the diagnosis of small cell lung cancer: comparative evaluation with neuronspecific enolase. Int J Biol Markers. 2001 JanMar;16(1):50-5.

88 Korse CM, Taal BG, Vincent A, van Velthuysen ML, Baas P, Buning-Kager JC, et al Choice of tumour markers in patients with neuroendocrine tumours is dependent on the histological grade. A marker study of Chromogranin A, Neuron specific enolase, Progastrin-releasing peptide and cytokeratin fragments. Eur J Cancer. 2012 Mar;48(5): $662-71$.

89 Al-Risi ES, Al-Essry FS, Mula-Abed WS. Chromogranin a as a biochemical marker for neuroendocrine tumors: A single center experience at royal hospital, oman. Oman Med J. 2017 Sep;32(5):365-70.

90 Korkmaz ET, Koksal D, Aksu F, Dikmen ZG, Icen D, Maden E, et al. Triple test with tumor markers CYFRA 21.1, HE4, and ProGRP might contribute to diagnosis and subtyping of lung cancer. Clin Biochem. 2018 Aug;58:15-9.

91 Johnson PW, Joel SP, Love S, Butcher M, Pandian MR, Squires L, et al. Tumour markers for prediction of survival and monitoring of remission in small cell lung cancer. Br J Cancer. 1993 Apr;67(4):760-6.

92 Micke P, Faldum A, Metz T, Beeh KM, Bittinger F, Hengstler JG, et al. Staging small cell lung cancer: Veterans Administration Lung Study Group versus International Association for the Study of Lung Cancer-what limits limited disease? Lung Cancer. 2002 Sep;37(3):271-6.

93 Petrović M, Bukumirić Z, Zdravković V, Mitrović S, Atkinson HD, Jurišić V. The prognostic significance of the circulating neuroendocrine markers chromogranin A, pro-gastrin-releasing peptide, and neuron-specific enolase in patients with small-cell lung cancer. Med Oncol. 2014 Feb;31(2):823.

94 Lyubimova NV, Churikova TK, Kushlinskii NE. Chromogranin as a biochemical marker of neuroendocrine tumors. Bull Exp Biol Med. 2016 Mar;160(5):702-4.

95 Harmsma M, Schutte B, Ramaekers FC. Serum markers in small cell lung cancer: opportunities for improvement. Biochim Biophys Acta. 2013 Dec;1836(2):255-72.

96 Gasser RW, Denz H, Huber H. [Tumor markers in bronchus cancer]. Wien Klin Wochenschr. 1989 Jul;101(14):476-9.

97 Modlin IM, Kidd M, Filosso PL, Roffinella M, Lewczuk A, Cwikla J, et al. Molecular strategies in the management of bronchopulmonary and thymic neuroendocrine neoplasms. J Thorac Dis. 2017 Nov;9(Suppl 15):S1458-73.

98 Wistuba II, Gazdar AF, Minna JD. Molecular genetics of small cell lung carcinoma. Semin Oncol. 2001 Apr;28(2 Suppl 4):3-13. 
99 Fernandez-Cuesta L, Perdomo S, Avogbe PH, Leblay N, Delhomme TM, Gaborieau V, et al. Identification of circulating tumor DNA for the early detection of small-cell lung cancer. EBioMedicine. 2016 Aug; 10: 117-23.

100 Khan MS, Tsigani T, Rashid M, Rabouhans JS, Yu D, Luong TV, et al. Circulating tumor cells and EpCAM expression in neuroendocrine tumors. Clin Cancer Res. 2011 Jan 15; 17(2):337-45.

101 Salgia R, Weaver RW, McCleod M, Stille JR, Yan SB, Roberson S, et al. Prognostic and predictive value of circulating tumor cells and CXCR4 expression as biomarkers for a CXCR4 peptide antagonist in combination with carboplatin-etoposide in small cell lung cancer: exploratory analysis of a phase II study. Invest New Drugs. 2017 Jun;35(3): 334-44.

102 Wang YL, Liu CH, Li J, Ma XP, Gong P. Clinical significance of circulating tumor cells in patients with small-cell lung cancer. Tumori. 2017 May;103(3):242-8.

103 Modlin IM, Drozdov I, Kidd M. The identification of gut neuroendocrine tumor disease by multiple synchronous transcript analysis in blood. PLoS One. 2013 May; 8(5):e63364.

104 Modlin IM, Aslanian H, Bodei L, Drozdov I, Kidd M. A pcr blood test outperforms chromogranin a in carcinoid detection and is unaffected by ppis. Endocr Connect. 2014;14: 14-0100.

105 Modlin IM, Frilling A, Salem RR, Alaimo D, Drymousis P, Wasan HS, et al. Blood measurement of neuroendocrine gene transcripts defines the effectiveness of operative resection and ablation strategies. Surgery. 2016 Jan;159(1):336-47.

106 Modlin IM, Kidd M, Bodei L, Drozdov I, Aslanian $\mathrm{H}$. The clinical utility of a novel blood-based multi-transcriptome assay for the diagnosis of neuroendocrine tumors of the gastrointestinal tract. Am J Gastroenterol. 2015 Aug;110(8):1223-32.

107 Pavel M, Jann H, Prasad V, Drozdov I, Modlin IM, Kidd M. Net blood transcript analysis defines the crossing of the clinical rubicon: when stable disease becomes progressive. Neuroendocrinology. 2017;104(2): 170-82.

108 Ćwikła JB, Bodei L, Kolasinska-Ćwikła A, Sankowski A, Modlin IM, Kidd M. Circulating transcript analysis (netest) in gep-nets treated with somatostatin analogs defines therapy. J Clin Endocrinol Metab. 2015 Nov; 100(11):E1437-45.
109 Bodei L, Kidd M, Modlin IM, Severi S, Drozdov I, Nicolini S, et al. Measurement of circulating transcripts and gene cluster analysis predicts and defines therapeutic efficacy of peptide receptor radionuclide therapy (PRRT) in neuroendocrine tumors. Eur J Nucl Med Mol Imaging. 2016 May;43(5): 839-51.

110 Modlin I, Drozdov I, Alaimo D, Callahan S, Teixeira N, Bodei L, et al. A multianalyte PCR blood test outperforms single analyte ELISAs (chromogranin A, pancreastatin, neurokinin A) for neuroendocrine tumor detection. Endocr Relat Cancer. 2014;21: 615-28.

111 Pęczkowska M, Cwikla J, Kidd M, Lewczuk A, Kolasinska-Ćwikła A, Niec D, et al. The clinical utility of circulating neuroendocrine gene transcript analysis in well-differentiated paragangliomas and pheochromocytomas. Eur J Endocrinol. 2017 Feb;176(2):143-57.

112 Malczewska A, Oberg K, Bodei L, Aslanian H, Lewczuk A, Filosso PL, et al. NETest Liquid Biopsy Is Diagnostic of Lung Neuroendocrine Tumors and Identifies Progressive Disease. Neuroendocrinology. 2019;108(3):219-31.

113 Modlin IM, Drozdov I, Kidd M. Gut neuroendocrine tumor blood qPCR fingerprint assay: characteristics and reproducibility. Clin Chem Lab Med. 2014 Mar;52(3):419-29.

114 Bodei L, Kidd M, Modlin IM, Prasad V, Severi $\mathrm{S}$, Ambrosini V, et al. Gene transcript analysis blood values correlate with ${ }^{68} \mathrm{Ga}$ DOTA-somatostatin analog (SSA) PET/CT imaging in neuroendocrine tumors and can define disease status. Eur J Nucl Med Mol Imaging. 2015 Aug;42(9):1341-52.

115 Halperin DM, Kulke MH, Yao JC. A tale of two tumors: treating pancreatic and extrapancreatic neuroendocrine tumors. Annu Rev Med. 2015;66:1-16.

116 Chen F, Zhang Y, Gibbons DL, Deneen B, Kwiatkowski DJ, Ittmann M, et al. Pan-cancer molecular classes transcending tumor lineage across 32 cancer types, multiple data platforms, and over 10,000 cases. Clin Cancer Res. 2018 May;24(9):2182-93.

117 Kidd M, Modlin IM, Drozdov I, Aslanian H, Bodei L, Matar S, et al. A liquid biopsy for bronchopulmonary/lung carcinoid diagnosis. Oncotarget. 2017 Dec;9(6):7182-96.

118 Lewis MA, Yao JC. Molecular pathology and genetics of gastrointestinal neuroendocrine tumours. Curr Opin Endocrinol Diabetes Obes. 2014 Feb;21(1):22-7.
119 Bowden M, Zhou CW, Zhang S, Brais L, Rossi A, Naudin L, et al. Profiling of metastatic small intestine neuroendocrine tumors reveals characteristic miRNAs detectable in plasma. Oncotarget. 2017 Apr;8(33):54331-44.

120 Li SC, Khan M, Caplin M, Meyer T, Öberg K, Giandomenico V. Somatostatin analogs treated small intestinal neuroendocrine tumor patients circulating micrornas. PLoS One. 2015 May; 10(5):e0125553.

121 Rapa I, Votta A, Felice B, Righi L, Giorcelli J, Scarpa A, et al. Identification of microRNAs differentially expressed in lung carcinoid subtypes and progression. Neuroendocrinology. 2015;101(3):246-55.

122 Yu Y, Zuo J, Tan Q, Zar Thin K, Li P, Zhu M, et al. Plasma miR-92a-2 as a biomarker for small cell lung cancer. Cancer Biomark. 2017;18(3):319-27.

123 Ranade AR, Cherba D, Sridhar S, Richardson P, Webb C, Paripati A, et al. MicroRNA 92a-2*: a biomarker predictive for chemoresistance and prognostic for survival in patients with small cell lung cancer. J Thorac Oncol. 2010 Aug;5(8):1273-8.

124 Greystoke A, Ayub M, Rothwell DG, Morris D, Burt D, Hodgkinson CL, et al. Development of a circulating miRNA assay to monitor tumor burden: from mouse to man. Mol Oncol. 2016 Feb;10(2):282-91.

125 Zhou R, Zhou X, Yin Z, Guo J, Hu T, Jiang $\mathrm{S}$, et al. Tumor invasion and metastasis regulated by microRNA-184 and microRNA574-5p in small-cell lung cancer. Oncotarget. 2015 Dec;6(42):44609-22.

126 Moldovan L, Batte KE, Trgovcich J, Wisler J, Marsh CB, Piper M. Methodological challenges in utilizing miRNAs as circulating biomarkers. J Cell Mol Med. 2014 Mar; 18(3):371-90.

127 Shapiro DE. The interpretation of diagnostic tests. Stat Methods Med Res. 1999 Jun;8(2): 113-34.

128 Stivanello M, Berruti A, Torta M, Termine A, Tampellini M, Gorzegno G, et al. Circulating chromogranin $\mathrm{A}$ in the assessment of patients with neuroendocrine tumours. A single institution experience. Ann Oncol. 2001;12(Suppl 2):S73-7.

129 Yang XO, Li JN, Qian JM, Yang H, Chen Q, Lu $\mathrm{L}$. [The diagnostic value of plasma chromogranin A in neuroendocrine tumors]. Zhonghua Nei Ke Za Zhi. 2011 Feb;50(2):124-7.

130 Baudin E, Gigliotti A, Ducreux M, Ropers J, Comoy E, Sabourin JC, et al. Neuron-specific enolase and chromogranin $\mathrm{A}$ as markers of neuroendocrine tumours. Br J Cancer. 1998 Oct;78(8):1102-7. 